\title{
Spatio-temporal variability and principal components of the particle number size distribution in an urban atmosphere
}

\author{
F. Costabile ${ }^{1,2}$, W. Birmili ${ }^{1}$, S. Klose ${ }^{1}$, T. Tuch ${ }^{1,3}$, B. Wehner ${ }^{1}$, A. Wiedensohler ${ }^{1}$, U. Franck ${ }^{3}$, K. König ${ }^{1}$, and \\ A. Sonntag ${ }^{1}$ \\ ${ }^{1}$ Leibniz Institute for Tropospheric Research (IfT), Permoserstrasse 15, 04318 Leipzig, Germany \\ ${ }^{2}$ National Research Council, Institute for Atmospheric Pollution (CNR), via Salaria km 29, 00016 Rome, Italy \\ ${ }^{3}$ Helmholtz Center for Environmental Research (UfZ), Permoserstrasse 15, 04318 Leipzig, Germany
}

Received: 18 July 2008 - Published in Atmos. Chem. Phys. Discuss.: 16 October 2008

Revised: 11 May 2009 - Accepted: 11 May 2009 - Published: 15 May 2009

\begin{abstract}
A correct description of fine (diameter $<1 \mu \mathrm{m}$ ) and ultrafine $(<0.1 \mu \mathrm{m})$ aerosol particles in urban areas is of interest for particle exposure assessment but also basic atmospheric research. We examined the spatio-temporal variability of atmospheric aerosol particles (size range 3-800 $\mathrm{nm}$ ) using concurrent number size distribution measurements at a maximum of eight observation sites in and around Leipzig, a city in Central Europe. Two main experiments were conducted with different time span and number of observation sites ( 2 years at 3 sites; 1 month at 8 sites). A general observation was that the particle number size distribution varied in time and space in a complex fashion as a result of interaction between local and far-range sources, and the meteorological conditions. To identify statistically independent factors in the urban aerosol, different runs of principal component (PC) analysis were conducted encompassing aerosol, gas phase, and meteorological parameters from the multiple sites. Several of the resulting PCs, outstanding with respect to their temporal persistence and spatial coverage, could be associated with aerosol particle modes: a first accumulation mode ("droplet mode", 300-800 nm), considered to be the result of liquid phase processes and far-range transport; a second accumulation mode (centered around diameters 90-250 nm), considered to result from primary emissions as well as aging through condensation and coagulation; an Aitken mode (30-200 nm) linked to urban traffic emissions in addition to an urban and a rural Aitken mode; a nucleation mode (5$20 \mathrm{~nm}$ ) linked to urban traffic emissions; nucleation modes
\end{abstract}

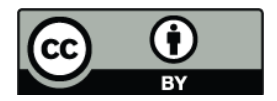

Correspondence to: W. Birmili (birmili@tropos.de)
(3-20 nm) linked to photochemically induced particle formation; an aged nucleation mode $(10-50 \mathrm{~nm})$. Additional PCs represented only local sources at a single site, or infrequent phenomena. In summary, the analysis of size distributions of high time and size resolution yielded a surprising wealth of statistical aerosol components occurring in the urban atmosphere over one single city. A paradigm on the behaviour of sub- $\mu \mathrm{m}$ urban aerosol particles is proposed, with recommendations how to efficiently monitor individual sub-fractions across an entire city.

\section{Introduction}

Atmospheric aerosol particles have been acknowledged to play a key role with respect to the global balance of climate (Haywood and Boucher, 2000; Stott et al., 2000; Ramanathan et al., 2001). Several aerosol effects, including optical absorption, scattering and cloud-activation are more sensitive to total particle surface area and number than total particle mass. Understanding the properties and the lifecycle of the entire particle size distribution is therefore required to assess aerosol-driven climate effects.

Besides climate, aerosol particles have been recognised as a potential adverse factor for human health (Pope et al., 2002; WHO, 2002; Oberdöster, 2005). While many of the health-related evidence has been based on $\mathrm{PM}_{10}$ mass concentrations as a particle metric, specific questions have arisen which particular aerosol types might be responsible, and how the exposure risk for the population may be reduced in a cost-efficient way. Specific sub-groups in the environmental

Published by Copernicus Publications on behalf of the European Geosciences Union. 
aerosol that are suspected to cause adverse health effects are, among others, carbonaceous aerosols, insoluble particles, traffic-related aerosols, metal aerosols, and ultrafine particles (diameter $<100 \mathrm{~nm}$ ) (HEI, 2002). A current trend in air quality monitoring is to refine the measurement techniques and thus identify the abundance (and later the possible health effects) of these aerosol sub-fractions.

A frequent observation is that atmospheric aerosol particles occur in particle modes, i.e. populations of similar size and chemical composition. Modes manifest themselves by a peak in the physical or chemical particle size distribution. Whitby (1978) popularised the tri-modal scheme including the coarse, the accumulation, and the "nuclei" (i.e. Aitken) mode, and this scheme has ever since been confirmed for different environments, refined and expanded (Ondov and Wexler, 1998; Mäkelä et al., 2000b; Birmili et al., 2001; Hussein et al., 2004; Heintzenberg et al., 2004; Morawska et al., 2008). In a remote background atmosphere these modes reflect the age and the life-time of the particles (Jaenicke, 1993), while in urban environments, they can reveal the proximity and/or activity of anthropogenic sources. Examples of tropospheric aerosol particle modes are the nucleation mode (Kulmala et al., 2004), the Aitken mode, the accumulation mode, the droplet mode resulting from liquid-phase processes (John, 1993), or the sea-spray mode in the coarse particle size range.

Being able to detect and describe aerosol particle modes can provide insight into the relevance of different aerosol sources and generation processes relevant in a particular section of the atmosphere. Knowledge on the spatio-temporal behaviour of aerosol modes could greatly simplify the description of aerosol-related processes and effects, and also particle exposure assessment. On the other hand, we always need to keep in mind the complex structure of the atmospheric aerosol - each single particle usually contains a different and complex mixture of chemical substances after a few days of residence in the atmosphere (Ebert et al., 2004), which means that any paradigm of particle modes can only be an approximation of the reality. The temporal and spatial variability of ambient aerosols has been the subject of many atmospheric studies. Sioutas et al. (2005) came to the conclusion that for ultrafine particles (UFPs; diameter $<100 \mathrm{~nm}$ ), measurements independent from total particle mass $\left(\mathrm{PM}_{10}\right.$, $\mathrm{PM}_{2.5}$, and even $\mathrm{PM}_{1}$ ) are needed to characterise their full impact on human health. While PM mass concentrations appear to be less variable in time and space, this is not true for particle number concentration, or the concentration of ultrafine particles.

Puustinen et al. (2007) studied in 4 European cities the correlation between ambient particle number and mass concentrations at a central site and a number of residential houses; their conclusion was that a central site measurement can be representative for a wide part of a city when referring to $\mathrm{PM}_{2.5}$ and $\mathrm{PM}_{10}$ mass concentration, but not for particle number. Hussein et al. (2005) showed for three pairs of sites that the number of ultrafine particles were less correlated between the sites than the number of bigger particles $(>100 \mathrm{~nm})$. Tuch et al. (2006) showed that the inter-site correlations of UFP concentrations within a city can turn to almost nil if one of the sites is traffic-influenced. In western cities, emissions from motor traffic are one of the main reasons for this lack of spatial correlations of UFPs (Ketzel et al., 2004; Bukowiecki et al., 2003).

A characterisation of the spatial distribution of exposure to ambient fine and ultrafine particles in a particular city requires, in any case, spatially-resolved UFP measurements and/or a coupled emission and transport modelling of UFPs across an urban landscape. Up to now, however, multiplepoint measurements of UFPs have been scarce, time series limited, and dispersion models mainly been available for local micro environments, at rough spatial resolution, or without a treatment of ultrafine particle dynamics.

In this work, we studied the temporal and spatial variations of sub- $\mu \mathrm{m}$ particle size distributions across a city in Central Europe (Leipzig, Germany) with the aid of multiple-site observations. Specific effects of urban and regional particle sources as well as urban meteorology are illustrated. Principal component analysis (PCA) is used to statistically isolate the main source and meteorological factors governing the particle number size distribution (PNSD) observed at the ensemble of sites. Particular emphasis is directed towards the dependency of temporal and spatial variations on particle size, and the consequences on spatial particle exposure. The paper concludes with a general paradigm on the behaviour of sub- $\mu \mathrm{m}$ particle modes in the area under study, and a recommendation how to efficiently monitor these particle subfractions across an entire city.

\section{Experimental}

\subsection{Field experiment and data}

Two main resources of atmospheric particle number size distributions (PNSDs) were used for this work: Long-term PNSD measurements were carried out at three observation sites during 2005 and 2006. The observation points included a street canyon, an urban background, and a rural background site.

Intensive spatial PNSD measurements were carried out at a maximum of eight observation sites between March and May 2005. The sites included one street canyon, another roadside, four urban background, one rural background, and an additional mobile site. Five out of the seven fixed measurement sites were concentrated within a distance of $3 \mathrm{~km}$ in the downwind plume of Leipzig's city centre. Data from this intensive spatial experiment are introduced here for the first time.

Figure 1 shows the location of the measurement sites on simplified maps of Leipzig (population ca. 500000 ) and its 
Table 1. Description of atmospheric PNSD measurements in Leipzig: (a) measurement sites, (b) instrumental parameters, measurement duration and number concentrations $N_{[10 ; 500]}$ during the intensive experiment 2005. For the location of the sites see Fig. 1.

(a)

\begin{tabular}{|c|c|c|c|c|c|}
\hline Site No. & Name & Type & Location & Traffic volume & Inlet height \\
\hline S1 & Schleussig & urban background & in a backyard & - & $\sim 18 \mathrm{~m}$ \\
\hline $\mathrm{S} 2$ & Inselstrasse & urban background & high above a low-trafficked street & - & $\sim 18 \mathrm{~m}$ \\
\hline $\mathrm{S} 3$ & Listplatz & roadside & near a highly trafficked square & $>50000$ vehday & $\sim 10 \mathrm{~m}$ \\
\hline $\mathrm{S} 4$ & Rabet & urban background & in a public park & - & $\sim 5 \mathrm{~m}$ \\
\hline S5 & Eisenbahnstrasse & roadside & inside a street canyon & $>10000 \mathrm{veh} /$ day & $\sim 6 \mathrm{~m}$ \\
\hline S6 & IfT & urban background & on the roof of the institute building & - & $\sim 16 \mathrm{~m}$ \\
\hline S7 & Melpitz & rural background & surrounded by pastures & - & $\sim 6 \mathrm{~m}$ \\
\hline S8a-d & mobile & roadside/urban background & variable & variable & $\sim 5 \mathrm{~m}$ \\
\hline
\end{tabular}

(b)

\begin{tabular}{ccccccc}
\hline Site No. & Name & Measurements period & Size spectrometer type & $D_{p}$ size range & Time resolution & $N_{[10 ; 500]}^{1}$ \\
\hline S1 & Schleussig & 18 March-31 May & Twin DMPS-IfT & $3-800 \mathrm{~nm}$ & $10 \mathrm{~min}$ \\
S2 & Inselstrasse & 7 April-9 May & SMPS-TSI 3080 & $10-500 \mathrm{~nm}$ & $6 \mathrm{~min}$ & 14.5 $(5.8)$ \\
S3 & Listplatz & 29 March-9 May & SMPS-IfT & $10-900 \mathrm{~nm}$ & $6 \mathrm{~min}$ & $17.1(12.5)$ \\
S4 & Rabet & 23 March-17 May & SMPS-IfT & $10-900 \mathrm{~nm}$ & $6 \mathrm{~min}$ & $6.1(3.0)$ \\
S5 & Eisenbahnstrasse & 1 March-31 May & Twin DMPS-IfT & $3-800 \mathrm{~nm}$ & $20 \mathrm{~min}$ & $19.2(9.8)$ \\
S6 & IfT & 1 March-31 May & Twin DMPS-IfT & $3-800 \mathrm{~nm}$ & $20 \mathrm{~min}$ & $9.9(5.2)$ \\
S7 & Melpitz & 1 March-31 May & Twin DMPS-IfT & $3-800 \mathrm{~nm}$ & $20 \mathrm{~min}$ & $5.0(3.6)$ \\
S8a-d & mobile & 7 April-27 May & SMPS-TSI 3080 & $10-500 \mathrm{~nm}$ & $6 \mathrm{~min}$ & $15 ; 10 ; 7.6 ; 5.8^{2}$ \\
\hline
\end{tabular}

1 mean value in $10^{3} \mathrm{p} . / \mathrm{cm}^{3}$ with standard deviation.

2 mean values for $\mathrm{S} 8 \mathrm{a}-\mathrm{d}$.

surroundings, with major urban geographical features indicated through lines and symbols. Compact information on the sites, such as instrumental parameters and mean particle number concentrations are provided in Table 1 . The numbering of the sites $(\mathrm{S} 1 \rightarrow \mathrm{S} 8)$ follows the prevailing wind direction from west to east.

\subsection{Measurement sites}

Site S1 (urban background): The temporary measurement site S1 was located in Leipzig's suburb "Schleussig", $4 \mathrm{~km}$ south-west of the city centre (Fig. 1, right box). To the west, the site borders a residential area with a dense pattern of fourstorey residential buildings. A wooded area of $2 \mathrm{~km}$ depth separates the site from the city centre on its eastern side. The site can be considered representative of urban background conditions in south-western Leipzig.

Site $S 2$ (urban background): The temporary measurement site S2 ("Inselstrasse") was located in a residential area approximately $1 \mathrm{~km}$ east of Leipzig's city centre (Fig. 1, lower left box). Site S2 can be taken representative of urban background conditions in the area between the city centre's high- trafficked ring road and the B2 national road, which crosses the eastern suburbs in a north-to-south direction.

Site S3 (roadside): The temporary observation site S3 ("Listplatz") was located near the crossing of several major roads, including the four-lane B2 national road. About 50000 vehicles pass by the site per day (Fig. 1, lower left box). S3 was therefore the site most influenced by road traffic among all observation sites used in our work. The sampling inlet was mounted on the third floor of an office building, facing a small park area eastward. Free atmospheric flow is warranted for the wind directions Southeast, East, North and Southwest, while for westerly winds, a vortex is expected to develop in the lee of the five-storey building block.

Site S4 (urban background): The temporary measurement site S4 ("Rabet") was located in a park, about $1.5 \mathrm{~km}$ distant from Leipzig's city centre (Fig. 1, lower left box). The site was singular in that an undisturbed advection was possible from almost all directions. The surroundings of the site were plain grassland, with only a few scattered trees. The nearest street was Eisenbahnstrasse street, about $200 \mathrm{~m}$ to the north, which is also the approximate distance to Site S5 (below). The measurements at the site $\mathrm{S} 4$ can be considered the 


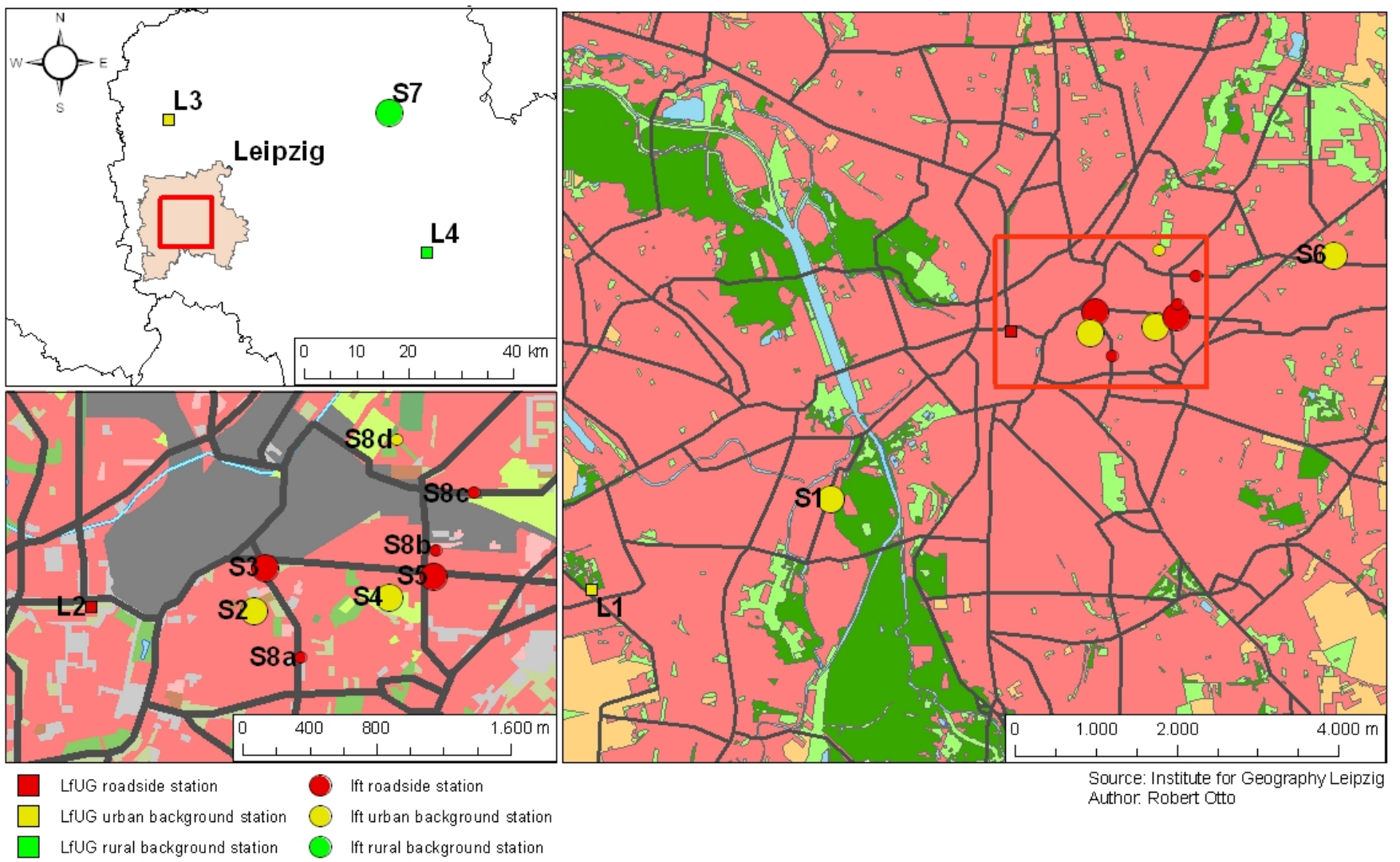

Fig. 1. Location of the atmospheric measurement sites during the experiment. Upper left map: Region around the city of Leipzig, Germany, with three regional background sampling sites S7, L3 and L4. Right map: city area of Leipzig with the urban background sampling sites S1, S6, and L1. Lower left map: The main urban area under investigation in eastern Leipzig, including the urban background sites S2, S4, and S8d, and the roadside sites S3, S5, S8a, S8b, S8c, and L2. Insets into the next bigger scale are indicated by red rectangles. The sites L1-4 represent routine observation sites by the Saxonian Office for the Environment and Geology (LfUG), Dresden.

best approximation of undisturbed urban background conditions in the eastern suburbs of Leipzig. The aerosol observations were supplemented by $\mathrm{NO}$ and $\mathrm{NO}_{2}$ measurements as well as wind speed and direction measurements by a sonic anemometer, $6 \mathrm{~m}$ above the ground.

Site S5 (roadside, also long-term measurements): Site S5 "Leipzig-Eisenbahnstrasse" is a permanent observation site in a street canyon about $2 \mathrm{~km}$ east of Leipzig's city centre (Fig. 1, lower left box). Particles are sampled at a height of $6 \mathrm{~m}$ above street level on the northern border of a regular street canyon. The canyon is traversed by a moderately trafficked arterial street carrying about 12000 vehicles per workday. Vehicles are counted continuously by an automated video detection system. A detailed description of the measurements is available in Klose et al. (2009). Auxiliary measurements include nitrogen oxide ( $\mathrm{NO}$ and $\mathrm{NO}_{2}$ ) collected in the street canyon, and 3-D-wind detected $4 \mathrm{~m}$ above roof-top level using a sonic anemometer.

Site S6 (urban background, also long-term measurements): The sampling site S6 "Leipzig-IfT" is situated on the roof of IfT's institute building, at a distance of about
$1.5 \mathrm{~km}$ east of site S5 (Fig. 1, right box). Aerosol particles are sampled at a height of $16 \mathrm{~m}$ above the ground. Highlytrafficked roads touch the area only at distances of at least $100 \mathrm{~m}$. Leipzig-IfT can be regarded as a location with a spatially homogenised urban background aerosol (Wehner and Wiedensohler, 2003). The aerosol measurements are supplemented by measurements of nitrogen oxide ( $\mathrm{NO}$ and $\left.\mathrm{NO}_{2}\right)$, sulfur dioxide $\left(\mathrm{SO}_{2}\right)$ and temperature.

Site 57 (rural background, also long-term measurements): In this work the atmospheric research station Melpitz serves as a rural background site, i.e. a site where urban influence is far. The station is located $50 \mathrm{~km}$ northeast of Leipzig (Fig. 1, upper left box). Flat grass lands, agricultural pastures and woodlands dominate the surroundings of the site within several tens of kilometers. Particle size distributions for an earlier period (2003-2004) were documented in Engler et al. (2007).

Additional sites $S 8 a-d$ : A mobile laboratory inside a van was deployed during the short-term spatial experiment to characterise further locations with respect to their particle exposure levels (S8a-d; cf. Fig. 1, lower left box). These 
included three roadside sites and an additional urban background site (Table 1b). The measurements at the sites S8a-d lasted only between one and three weeks per site. Hence, these data were not processed statistically, and served for illustration only.

Official monitoring sites L1-4: The body of particle size distribution data at the sites $\mathrm{S} 1-8$ was complemented by routine observations at four additional stations of the LfULG (Saxonian Office for the Environment and Geology) network (Fig. 1). The sites were "Leipzig-Mitte" (L1, roadside), "Leipzig-West" (L2, urban background), "Collm" (L3) and "Delitzsch" (L4), both regional background. The measurements include $\mathrm{PM}_{10}$ mass concentration, the mixing ratios of $\mathrm{NO}, \mathrm{NO}_{2}, \mathrm{SO}_{2}, \mathrm{O}_{3}$, and $\mathrm{CO}$, BTX (benzene/toluene/xylene) and basic meteorological parameters. These data served primarily to characterise the large-scale pollution situation in Leipzig.

\subsection{Instrumental}

Particle number size distributions (PNSD) were determined at multiple sites using particle mobility spectrometers. The designs used were a) the custom-built twin differential mobility particle sizer (TDMPS) on the basis of Vienna-type differential mobility analysers and using dry sheath air (Birmili et al., 1999), b) the scanning mobility analyser (SMPS) similar to a) but using a closed-loop sheath circulation and operating in scanning mode, and c) the commercial SMPS, model 3080 (TSI Inc., St. Paul, MN, USA). The deployment of the eight instruments is indicated in Table 1b. Andersen $\mathrm{PM}_{10}$ sampling inlets were deployed at each site to remove coarse particles.

In order to achieve a maximum comparability of the size distribution measurements at different sites, frequent instrumental intercomparisons were conducted. As a matter of convenience, site S5 was selected as the central comparison site during the short-term spatial experiment in 2005. Before and after deployment of the mobility spectrometers at the sites S1-4, S6 and S8, the corresponding instruments were compared against the TDMPS at site S5 for a period of at least three days using ambient aerosol. From these intercomparison experiments, particle losses (due to diffusion) in each instrument were quantified as a function of particle size, and taken into account in the final version of the measurement data. Besides correcting for diffusion losses, we corrected for deviations in size channels between the different instruments in that they were normalised to the dry conditions (i.e. $\mathrm{RH}<5 \%$ ) prevailing in the instrument at site S5.

Concretely, we first checked whether the sizing of an individual instrument was correct in relation to the central reference instrument at site S5. Deviations with respect to particle sizing were quantified on the basis of ambient aerosol episodes when the size distributions showed modal peaks, usually in the size range $40-100 \mathrm{~nm}$. The deviations in particle size with respect to the reference instrument at site S5 were between 0 and $6 \%$. The deviations were not surprising because some size spectrometers were using a recirculated sheath air involving relative humidities up to $30 \%$ while others (including the reference instrument) were running on a dry sheath air.

Having determined the deviation in particle sizing for each instrument, the size distribution diameters were scaled back accordingly, thereby generating size distributions equivalent to dry sheath air conditions. We are aware of the limitations of this procedure, for instance because the hygroscopic particle growth of particles inside a moist sheath air is not expected to be constant for all particle sizes. We nevertheless think that the method performs rather well for the region of the size distributions where usually the maximum in particle number occurs. After adjusting the particle diameters, the number concentration efficiency of each individual size spectrometer was determined by comparing its data to those of the reference instrument. These size-dependent number concentration efficiencies were then applied onto each instrument's data set, respectively, thus generating the final size distributions. After the corrections described, we estimate the measurements from different sites to be comparable within $10 \%$ of particle number.

\section{Data analysis}

The data-sets from both the long-term and the intensive spatial experiment were processed by Principal Component Analysis (PCA). PCA is a classical technique for dimensionality reduction, which has found plenty of environmental applications including atmospheric aerosol research (Chan and Mozurkewich, 2007a; Huang et al., 1999). To avoid confusion we will use the term "STA" (statistical analysis) instead of "PCA" when referring to a particular PCA run rather than to the method in general.

Table 3 lists the five different statistical analyses (STA) conducted for this work. The five analyses are different in that they cover different amounts of data, making varying compromises between the number of observation sites, and time series length. In each analysis STA $l, l$ indicates the number of sites whose data were co-analysed. STA1/STA3 and STA7 represent the cornerstones of the work, with STA1/STA3 using two years of simultaneous data at three sites, and STA7 using 17 days of data at seven sites. The difference between STA1 and STA3 was that in STA1, the PCA was carried out for the data from each site individually, while in STA3 the data from all sites were combined and coanalysed. In STA4, STA6 and STA7 the data from all $l$ sites were also co-analysed.

In practice, the particle size distribution data in $d N / d \log D_{p}$ were first $\log$-normalised, and then standardised to a zero mean and unit standard deviation. The normalised values (simply $N$ hereafter) were arranged in five matrices, N1, N3, N4, N6, N7. In analogy to STAl, 
the number indicates the number of measurement sites whose data were combined into a single analysis. In a matrix Nl, each of the $p$ columns represents a standardised concentration value $N$, varying with site as well as particle diameter, and each row represents the combined 30-min average observations at all sites simultaneously.

Subsequently, the data matrices were by PCA into a representation based on a new set of orthogonal variables, i.e. principal components (PCs). Detailed descriptions of the PCA method have been given in a number of textbooks (e.g., Gnanadesikan, 1977; Morrison, 1976; Mulaik, 1972). Briefly, the variable transformation is achieved by rotating the existing system of orthogonal coordinates $N_{1} \ldots N_{p}$ into a new system of orthogonal, uncorrelated variables (PCs) with their associated eigenvectors. The PCs were obtained by Varimax rotation, i.e. a fraction as large as possible of the total variance in the data set shall be attributed to a number of PCs as little as possible. A major asset of PCA is that large environmental data sets with many input variables can often be reduced drastically to a simplified description using only a few PCs without the loss of relevant information.

Several criteria have been developed to identify the number of PCs $(q)$ that should be retained as relevant for the description of the data set. In our work we used a combination of the Kaiser criterion (i.e. retention of PCs whose eigenvalue is greater than 0.65-1) (Pugatshova et al., 2007; Eder, 1989) as well as scree plot criteria (e.g., Chan and Mozurkewich, $2007 \mathrm{~b}$ ) to determine the final number of PCs to retain. Also, the retained $\mathrm{PCs}_{\mathrm{PC}} \ldots \mathrm{PC}_{k}$ were arranged in decreasing order of their variance explained $\left(\lambda_{k}\right)$, i.e. PC1 is the component exhibiting the largest single variance. $\lambda_{k}$ is also called the eigenvalue of $\mathrm{PC}_{k}$. Each eigenvector is composed of scalar coefficients, which describe the new PCs as a linear combination of the original variables $N_{1} \ldots N_{p}$. The coefficients thus represent the relative weight of each original variable in each PC. The so-called "factor loadings" represent the coefficients for $\mathrm{PC}_{k}$ scaled by the amount of variance $\lambda_{k}$ explained by this PC (eigenvalue). They thus represent the relative weight of each variable in each $\mathrm{PC}$ re-scaled by the amount of variance explained by the PC.

Since the variables $N$ had different scales, we decided to work with correlations instead of covariances. Hence, it was possible to directly link the loadings to the correlations among the original variables within each PC. Also, the eigenvectors with the largest eigenvalues corresponded to the dimensions with the strongest correlation in the data set.

Finally, the time scores of the new PCs - estimated by the loadings and the standardised values of $N$, were used as an input for a consecutive principal component analysis (STAc) including additional variables, i.e. pollutant concentrations, meteorological parameters and traffic volume. The goal of STAc was to relate the new PCs with these environmental variables and hence to provide some evidence on the atmospheric processes or particle sources associated with the new PCs. In STAc, the additional parameters were again log- scaled and standardised to zero mean and unit variance whilst the scores from STA1, STA3, STA4, STA6, and STA7 were not standardised again.

\section{Results}

\subsection{Basic phenomenology}

\subsubsection{Mean particle number size distribution}

To illustrate several basic features of our experimental data, mean particle number size distributions (PNSD) as well as selected case studies are presented. Figure 2 shows the mean PNSD of the two main data sets. The upper part of the Figure represents 2 years of measurements at 3 sites, i.e. the longterm experiment, while the lower part shows the statistics of almost 2 months of measurements at 7 sites, i.e. the intensive spatial experiment.

It is very apparent that the mean particle number concentrations increase with decreasing distance to the main anthropogenic source, motor traffic. Below $300 \mathrm{~nm}$ particle diameter, the mean concentration at the traffic site S5 is up to one order of magnitude higher than at the rural site Melpitz, located $50 \mathrm{~km}$ downstream of Leipzig. Above $300 \mathrm{~nm}$, however, the differences become minor, because these particles represent to a greater extent the long-lived regional aerosol.

The standard deviation of the PNSD shows a similar behaviour, albeit less obvious with respect to the proximity to the traffic sources. It is common to all sites that the highest variance in the data occurs in the UFP size range, particularly below $40 \mathrm{~nm}$. Not unexpectedly, the traffic sites (S3 and S5) feature the highest variances, with wide local maxima in two modes between 10-20 and 50-100 nm, respectively. At both urban background and rural sites (S1, S2, S4, S6, and S7) the variance exhibits one local maximum around 20 , and $70 \mathrm{~nm}$, and another around $200 \mathrm{~nm}$. The concentration variance is the lowest at the rural site with the exception of the size range below $20 \mathrm{~nm}$.

\subsubsection{Multiple-site case studies}

Six case studies are now presented to visualise the spatio-temporal variability of the PNSD, ranging from "homogeneous cases", i.e. such where the PNSD agreed rather well at different observation sites to rather heterogeneous cases. A rough count was made of the homogeneous vs. the heterogeneous cases for the period of the intensive spatial experiment in 2005, about 6 weeks long. As a result, the PNSD could be described as rather homogeneously distributed across the city on half of the days, but rather inhomogeneously distributed during the other half. The degree of homogeneity depends on the activity of anthropogenic sources combined with the weather, and is explored in the following six case studies. 
(a)

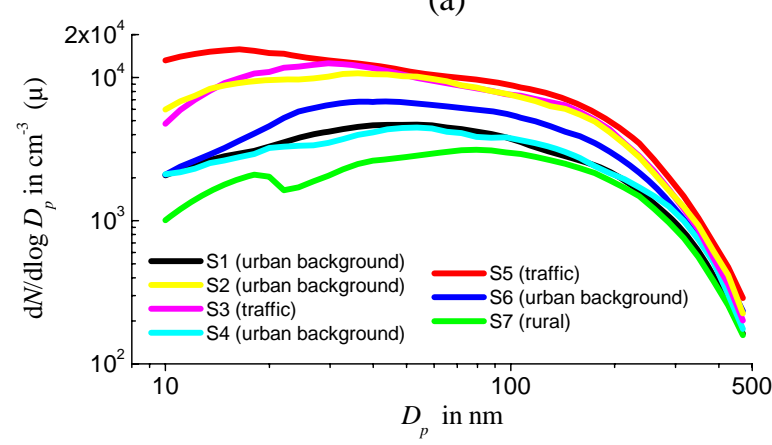

(c)

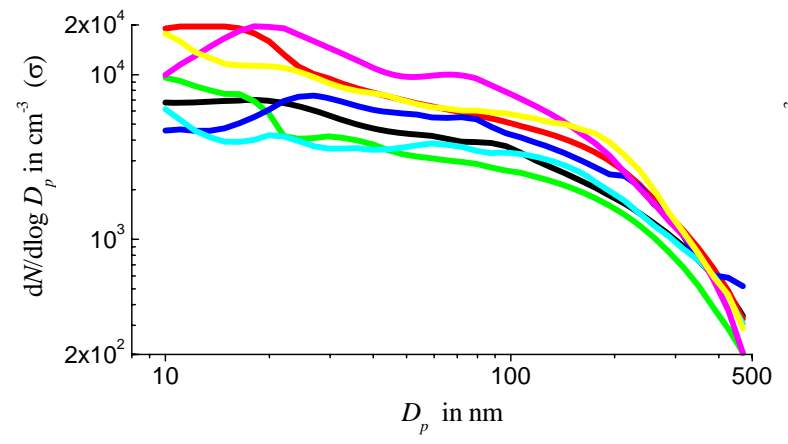

(b)

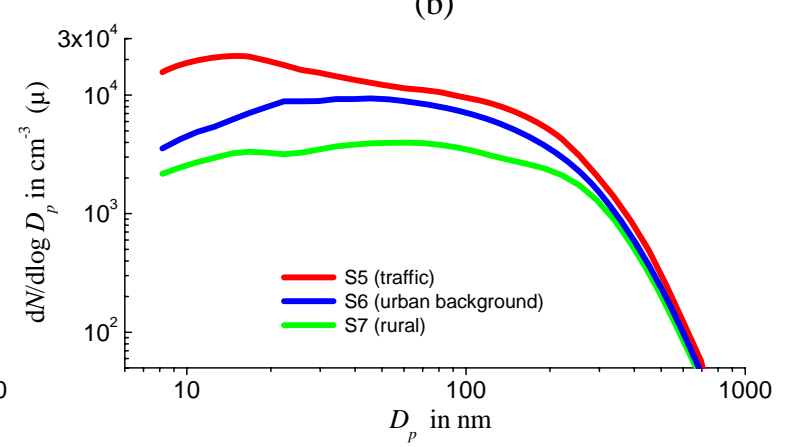

(d)

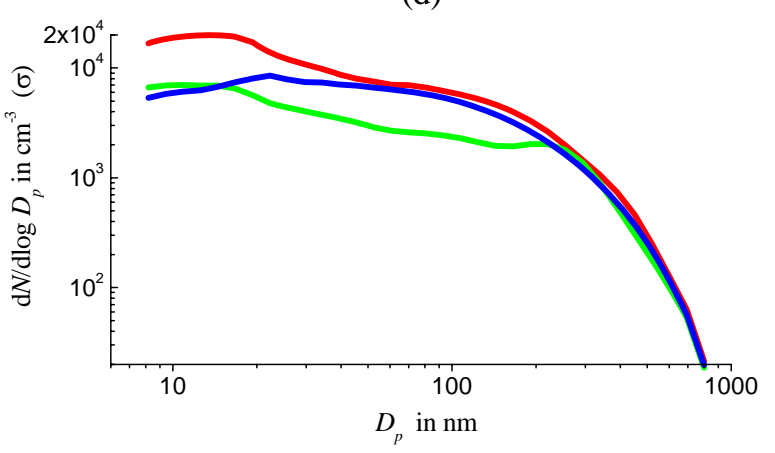

Fig. 2. Mean $(\mu)$ particle number size distributions with standard deviation $(\sigma)$ in Leipzig: (a) $\mu$ for the spatial intensive campaign in 2005 , (b) $\mu$ for the long-term experiment (2005-2006), (c) $\sigma$ for a, (d) $\sigma$ for b.

\section{April: High spatial homogeneity of aerosols under sunny} conditions

Figure 3a illustrates the PNSD measured on 3 April 2005. Size distributions were measured at 6 sites in Leipzig concurrently. (Two sites included in the full set-up were not operational yet.) Since the day was a Sunday, the influence of traffic was low compared to weekdays. The levels of solar radiation indicate a cloudless day under relatively constant and slow south-easterly winds. The day started with $\mathrm{PM}_{10}$ mass concentrations up to $40 \mu \mathrm{g} \mathrm{m}^{-3}$ in the rural background (sites $\mathrm{L} 1$ and L3), and up to $50 \mu \mathrm{g} \mathrm{m}^{-3}$ within the city (sites L2 and L4). $\mathrm{SO}_{2}$ concentrations (not shown) were around $6 \mathrm{ppbV}$. After 10:00 h LT, $\mathrm{PM}_{10}$ concentrations started to decreased significantly, most likely as a result of vertical dilution with cleaner air aloft. This decrease can also be clearly seen in all particle size distributions in the shape of a decrease of Aitken and accumulation mode particle number concentrations (Fig. 3a). The minimum in accumulation mode number concentration was reached at all sites simultaneously after 15:00 h.

In the contour diagrams it can be seen that new secondary particles - suggested to originate from photochemical processes, were formed at all sites. The "banana"-shaped events were characterised by an increase in particle number concentrations below $10 \mathrm{~nm}$ around 10:00 h. It can be seen very clearly that this increase happened simultaneously at all sites, including the rural site Melpitz (S7), which is distant at $50 \mathrm{~km}$. The smooth evolution of the size distributions involving particle formation and subsequent growth suggests a very high spatial homogeneity of the aerosol across the entire city and its surroundings. This homogeneity can be observed despite the sites not being aligned with respect to the prevailing southerly wind (cf. Fig. 1). The case of 3 April 2005 demonstrates that under sunny conditions and reduced traffic emissions (Sunday) the particle size distribution can be distributed very homogeneously in space over at least $50 \mathrm{~km}$, even including urban zones.

\section{April: High spatial homogeneity of aerosols under cloudy conditions}

Figure $3 \mathrm{~b}$ illustrates, like the previous example, a case of high spatial homogeneity of the PNSD as well as PM $_{10}$ concentration across the entire Leipzig area. (From here, PNSD measurements were operational at 8 sites simultaneously.) In contrast to Fig. 3a, this day (24 April 2005) was cloudy, with north-east being the prevailing wind direction. Generally, relatively smooth changes in PNSD can be seen throughout the day; between midnight and the afternoon (14:00 h), a nearly constant Aitken mode dominates the size distribution. Its mode diameter slowly shifts from $40 \mathrm{~nm}$ to about $70 \mathrm{~nm}$ during the morning. Between 14:00 and $17: 00 \mathrm{~h}$, an event of secondary particle formation $(<20 \mathrm{~nm})$ 

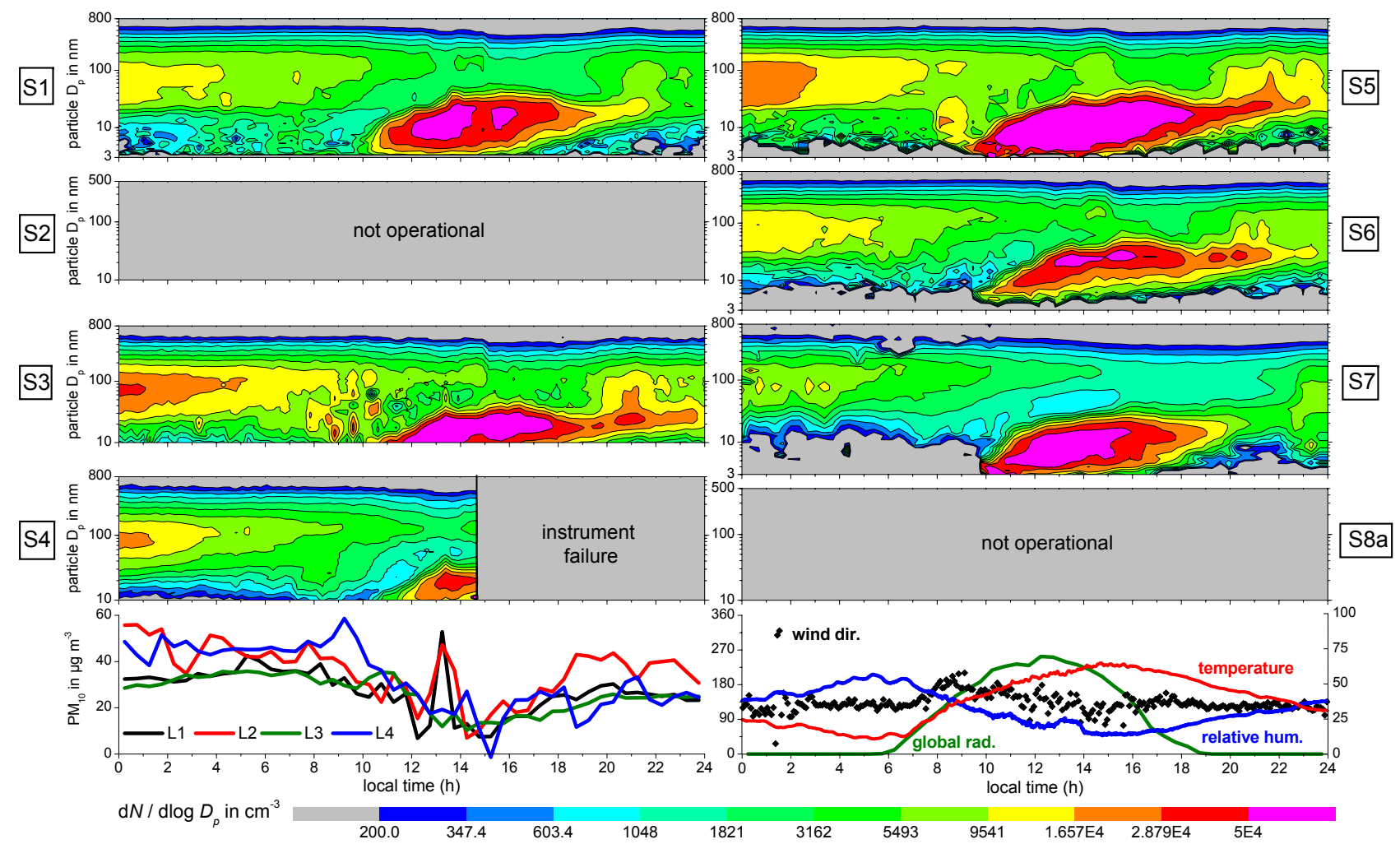

(a)
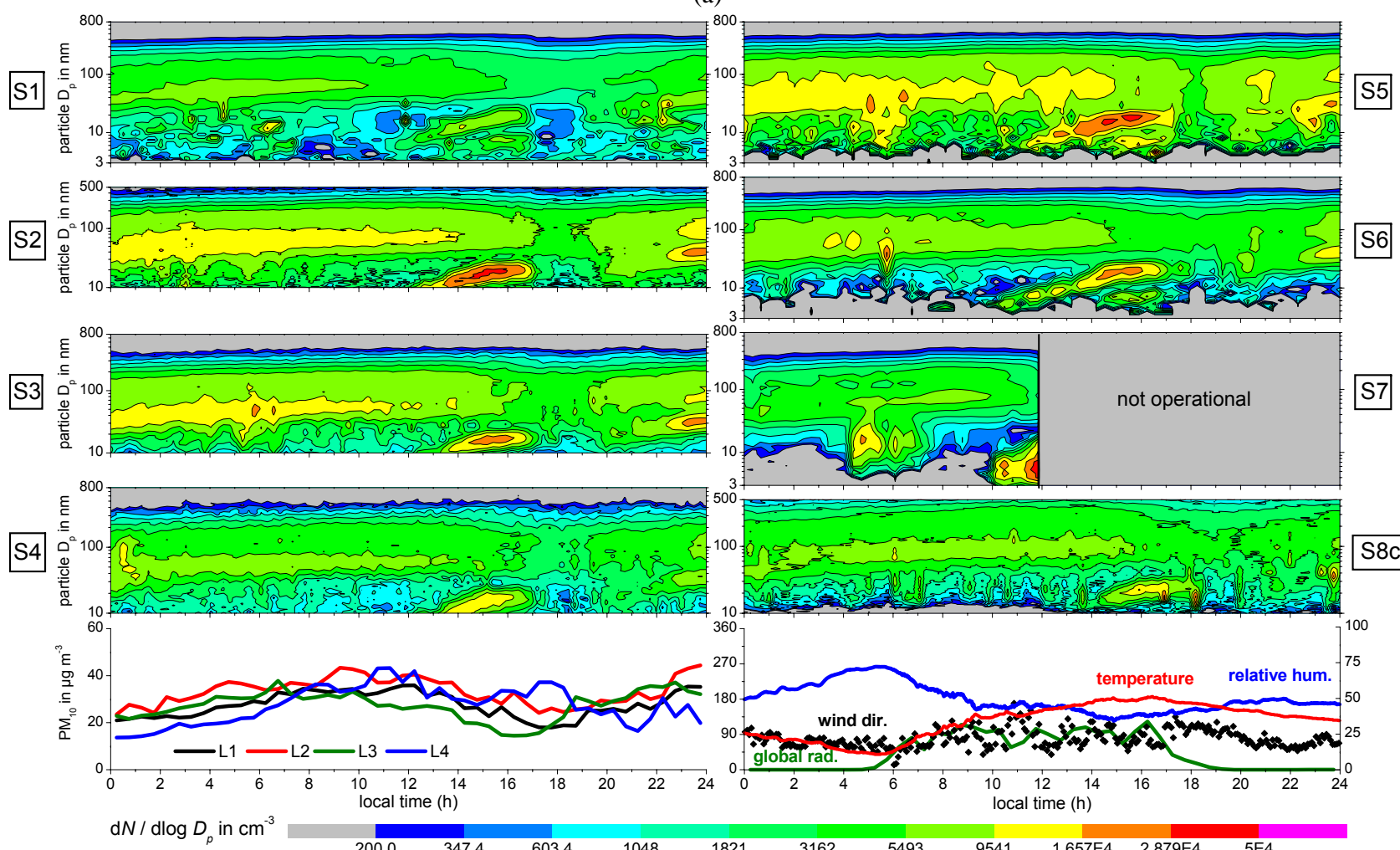

(b)

Fig. 3. Particle number size distributions on (a) 3 April 2005 (Sunday) and (b) 24 April 2005 (Sunday). PM 10 mass concentrations are taken from the LfULG network. Meteorological parameters originate from site S6 except wind direction (S5). Wind direction is indicated in $1^{\circ}$ (left axis), temperature in $10^{\circ} \mathrm{C}$ (left axis), global radiation in $10 \mathrm{~W} \mathrm{~m}^{-2}$ (right axis), and relative humidity in $\%$ (right axis). 

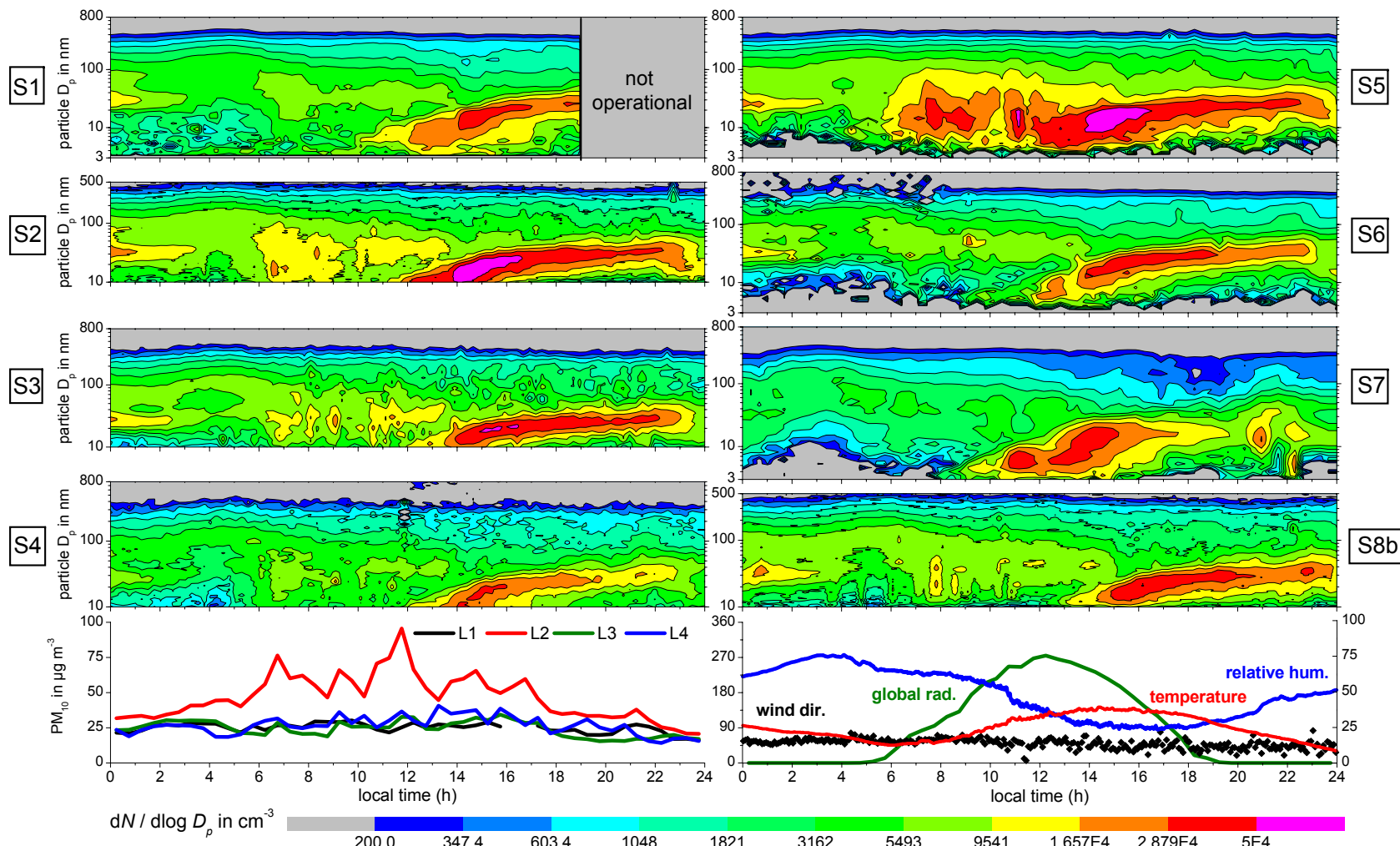

(c)
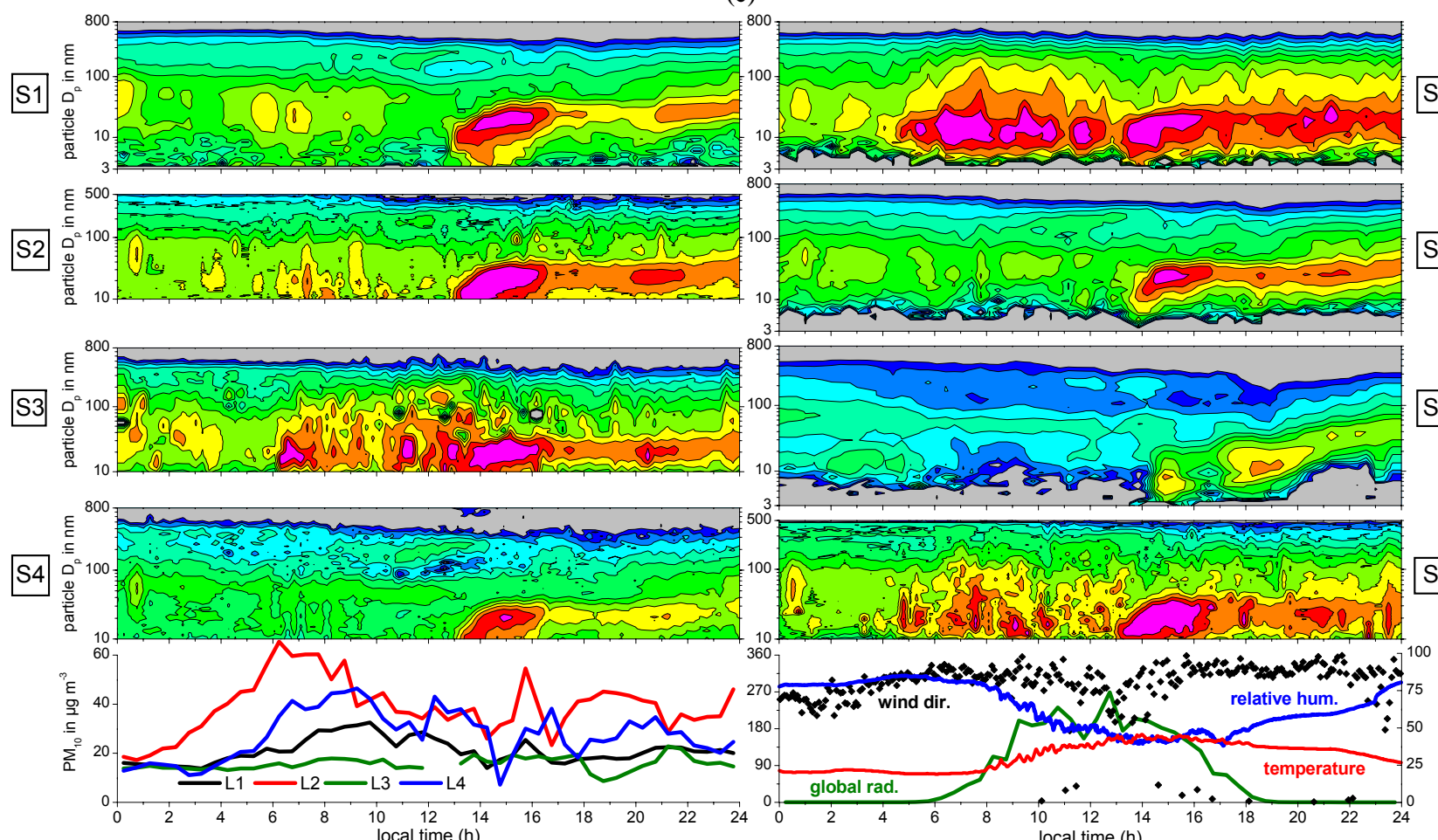

$$
\mathrm{d} N / \mathrm{d} \log D_{p} \text { in } \mathrm{cm}^{-3} \quad \begin{array}{lllll}
200.0 & 347.4 & 603.4 & 1048 & 1821
\end{array}
$$

(d)

Fig. 3. Continued. Particle number size distributions on (c) 20 April 2005 (Wednesday) and (d) 11 April 2005 (Monday). PM 10 mass concentrations are taken from the LfULG network. Meteorological parameters originate from site S6 except wind direction (S5). Wind direction is indicated in $1^{\circ}$ (left axis), temperature in $10^{\circ} \mathrm{C}$ (left axis), global radiation in $10 \mathrm{~W} \mathrm{~m}^{-2}$ (right axis), and relative humidity in $\%$ (right axis). 



(e)
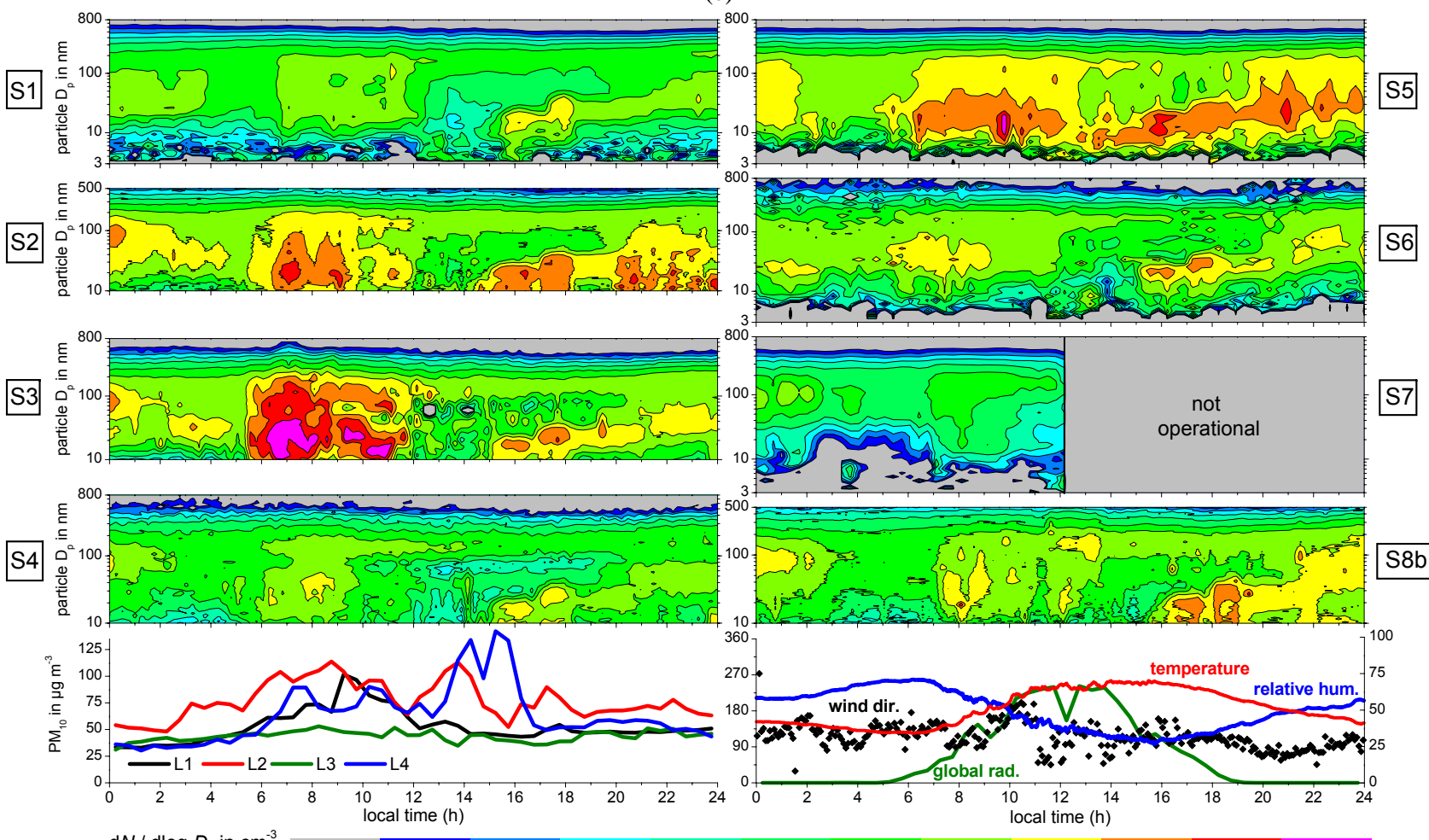

$\mathrm{d} N / \operatorname{dlog} D_{p}$ in $\mathrm{cm}^{-3}$
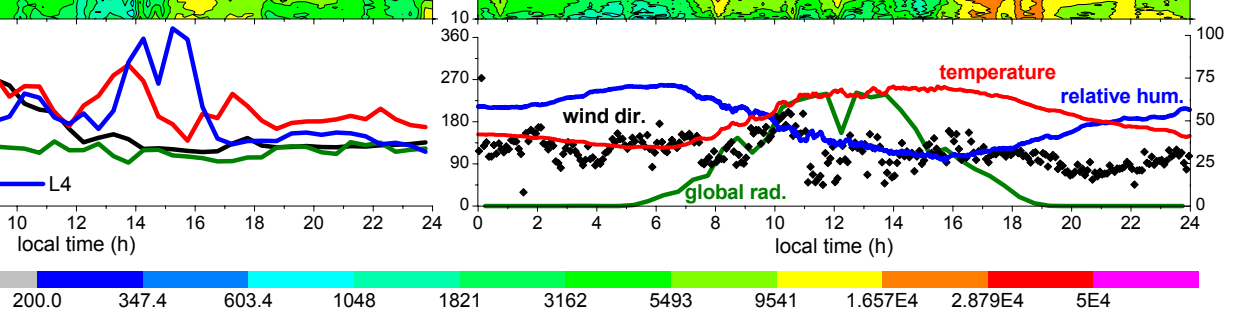

(f)

Fig. 3. Continued. Particle number size distributions on (e) 12 April 2005 (Tuesday) and (f) 15 April 2005 (Friday). PM 10 mass concentrations are taken from the LfULG network. Meteorological parameters originate from site S6 except wind direction (S5). Wind direction is indicated in $1^{\circ}$ (left axis), temperature in $10^{\circ} \mathrm{C}$ (left axis), global radiation in $10 \mathrm{~W} \mathrm{~m}^{-2}$ (right axis), and relative humidity in \% (right axis). 
can be seen, which is evidenced by the slow growth of its nucleation mode (Fig. 3b). Its peak concentrations were, however, much lower than on the case shown in Fig. 3a. This second weekend case demonstrates that the particle size distribution can be homogeneously distributed in space under various wind directions and in the presence of clouds as well.

\section{April: A weekday with secondary new particle formation}

Figure $3 c$ illustrates the dynamics of the in the PNSD on a weekday, 20 April 2005. Like in Fig. 3b, the wind direction was north-easterly, but the wind speed was considerably higher and intensive solar radiation prevailed. $\mathrm{PM}_{10}$ mass concentrations were very similar across the entire region $\left(25 \mu \mathrm{g} \mathrm{m}^{-3}\right)$ except at the city centre site L2 (up to $100 \mu \mathrm{g} \mathrm{m}^{-3}$ ), which suffered from exceptional local contamination by construction activities at the time. In Fig. 3c, a clear impact of traffic emissions can be seen in the morning between 06:00 and 10:00 h at the traffic site S5. It can be recognised as a size distribution peak around $20 \mathrm{~nm}$. (It is worth mentioning that the street canyon at site S5 is oriented in east-west direction, and that the northerly winds place the sampling inlet there in the leeward position of the traffic this is the supposed reason for the high concentrations here.)

A "banana"-shaped event of new particle formation and growth starts around 12:00 $\mathrm{h}$ across the entire city. The start time can be determined with confidence at those sites with $3 \mathrm{~nm}$ as a lower cut-off diameter of the measurement (S1, $\mathrm{S} 5, \mathrm{~S} 6$, and S7); at the sites with $10 \mathrm{~nm}$ cut-off, the event can only be detected with a noticeable delay. The rural site makes an exception in that the formation event starts earlier, before 10:00 h, which indicates a certain spatial inhomogeneity of the formation event. It is worth mentioning that around 14:00 $\mathrm{h}$ the particle mode originating from the traffic emissions in the morning disappears almost completely, and at all the urban sites (Fig. 3c). This disappearance is again interpreted as the impact of vertical mixing rather than the decrease of traffic emissions because real-time traffic counts suggest a nearly unchanged traffic volume until 18:00 h. The case of 20 April 2005 demonstrates urban and regional spatial homogeneity of the aerosol again, however, with limitations at the traffic sites and the distant rural site.

\section{April: A weekday with limited pollution impact}

Figure 3d illustrates a weekday case under slow westerly winds. In contrast to the previous cases, the $\mathrm{PM}_{10}$ concentrations were quite inhomogeneous across the entire region. Low background aerosol concentrations can be seen best in $\mathrm{PM}_{10}$ at site $\mathrm{L} 3$, and in low accumulation mode concentrations at the sites S7 (rural), S1 and S4 (both urban background). The influence of motor traffic manifests itself throughout most of the day, starting just before $05: 00 \mathrm{~h}$, and highly evident at S3, S5, and S8a, which are all roadside observation sites. The impact of traffic can also be seen in high levels of $\mathrm{NO}_{\mathrm{x}}$ (not shown). The highest traffic-induced concentrations occurred at site S5. Fluctuations in the traffic signal can be best seen at the temporary site S8a, which had measurements at a high time resolution of 6 min. Individual peak concentrations could also be detected at site $\mathrm{S} 2$, which was therefore considered as the urban background site influenced most directly by traffic sources.

The pattern of fluctuating signals caused by traffic sources are overlayed by a secondary particle formation event starting at 13:00 across the entire city (S1-S6, and S8a). This occurred under sunny conditions when the horizontal wind speed (not shown) reached a minimum. Like the previous cases, and as in many examples in the literature, vertical mixing was a factor associated with the formation event. As can be seen especially for site S5 in Fig. 3d, the signal of the secondary particles overlays with the traffic-derived particles after 16:00 h. Both cannot be distinguished any more. At the rural site S7, the particle formation event appears not to be the same as in the city, with lower concentrations and a significant time delay, which indicates spatial inhomogeneity. In summary, Fig. 3d demonstrates a very inhomogeneous spatial distribution of nearly all aerosol components, with the single exception of a secondary particle formation event that occurred across the entire city.

\section{April: A weekday with high pollution impact}

Figure 3e illustrates another case - 12 April 2005, when the impact of local sources can be clearly seen across the entire city of Leipzig. Several features were similar to Fig. 3d, such as the slow winds, the great regional inhomogeneity of $\mathrm{PM}_{10}$. However, the solar radiation was even lower, thereby providing less convective forcing to facilitate vertical atmospheric mixing. As a consequence, the impact of local sources, most of all traffic, can be seen throughout almost the entire $24 \mathrm{~h}$. Very high particle concentrations (more than $50000 \mathrm{~cm}^{-3}$ in $d N / d \log D_{p}$ ) could be seen over several hours at the traffic sites S3, S5, and S8a, while this value was reached briefly at the background sites S2 and S6 as well. In summary, this day demonstrates the possibility of high anthropogenic aerosol concentrations at many sites across the entire city of Leipzig. Poor mixing prevailed, which is also symptomatic in the way that no secondary particle formation could be observed on this day.

\section{April: A weekday featuring several aerosol types}

Figure 3e shows a last case study, featuring the succession of several aerosol types across the city during relatively warm weather on 15 April 2005 (up to $27^{\circ} \mathrm{C}$ ). The impact of traffic emissions in the morning can be seen at all sites, sharply delimited between 06:00 and 12:00 h. On this morning, the highest particle number concentrations occurred at site S3, which illustrates that the ultimate amplitudes of the signals at the traffic sites S3 and S5 are not scalable with each other 
Table 2. Description of the 5 multivariate analyses (STA1, STA3, STA4, STA6, and STA7). In "STAl" the index indicates the number of sites included in each principal component analysis.

\begin{tabular}{lccccc}
\hline Name & $\begin{array}{c}\text { Observation } \\
\text { sites used }\end{array}$ & $\begin{array}{c}\text { Measurement } \\
\text { duration }\end{array}$ & $\begin{array}{c}\text { Measurement } \\
\text { period }\end{array}$ & $\begin{array}{c}\text { Particle } \\
\text { size range }\end{array}$ & Comment \\
\hline STA1 & S5-S7 & 2 years & 2005 and 2006 & $3-800 \mathrm{~nm}$ & 3 sites individually, long-term \\
STA3 & S5-S7 & 2 years & 2005 and 2006 & $3-800 \mathrm{~nm}$ & 3 sites combined, long-term \\
STA4 & S1, S5-S7 & 70 days & March-May 2005 & $3-800 \mathrm{~nm}$ & 4 sites combined, wide size range \\
STA6 & S1-S6 & 33 days & April-May 2005 & $10-470 \mathrm{~nm}$ & 6 urban sites combined, limited size range \\
STA7 & S1-S7 & 17 days & April 2005 & $10-470 \mathrm{~nm}$ & 7 sites combined, largest spatial coverage \\
\hline
\end{tabular}

but likely depend on the micrometeorological factors (wind) in their immediate surroundings. Between 02:00 and 05:00, a local plume of particles centered around $30 \mathrm{~nm}$ could be detected exclusively at the neighbouring sites S2 and S3. This example shows that multiple-site measurements are needed if such local plumes of a scale of a few 10 or $100 \mathrm{~m}$ should be resolved.

In the afternoon, a double-peaked plume could be detected across the entire city between 15:00 and 19:00. It shows two subsequent and distinguished modes centered around 20 and $30 \mathrm{~nm}$, respectively. It is intriguing that such a plume of relatively moderate concentration (compared, e.g., to the particle formation events shown above) can be detected across the entire city. The most persistent aerosol mode, both in time and space, was an accumulation mode centered around $150 \mathrm{~nm}$. It prevailed after 08:00 h, and could be seen in almost pure shape at the sites S1, S2, S3, S4, and the low-trafficked roadside site $\mathrm{S} 8 \mathrm{~b}$, while it was masked by local emissions especially at site S5. This last case study reveals some unexpected spatial correlations of aerosol components across the entire city, but also several small-scale phenomena which could be seen at a maximum of two sites.

The six case studies reveal a wide spectrum of sizesegregated aerosol components that occur across the urban atmosphere under study. In order to capture the wealth of information contained in such an urban atmosphere, spatially resolved measurements are clearly advisable. Meanwhile, clear correlations between different observation sites were found for particle populations across the entire sub- $\mu \mathrm{m}$ particle size spectrum. Such correlations concerned the biggest particles in the accumulation mode (also seen in total particle mass), but also the smallest detectable particles in the nucleation mode. To evaluate the relevance of the phenomena described, the data sets were analysed statistically; this is provided in detail in the following.

\subsection{Multiple-site principal components in the PNSD}

In the previous Section we showed the existence of largescale components (i.e. such being representative for a larger spatial scale) of the PNSD. Here, the results of the principal component analysis (PCA) at single (STA1) and multiple sites (STA3, STA4, STA6, and STA7) are presented, which characterise co-variations in the PNSD both in space and time. Table 3 compiles the aerosol particle modes resulting from the different statistical analyses.

\subsubsection{Single-site principal component analysis}

Figure 4 shows the results of principal component analyses carried out for the long-term particle size distribution data at each of the three sites S5, S6, and S7 separately. These analyses correspond to STA1 listed in Table 2. Importantly, STA1 is able to extract all the modes identified above in terms of local maxima in the size distribution of the particle number variance. Six very similar principal components (PCs) could be extracted from the data at each site. The loadings of PC2 peak in the nucleation mode $(5-25 \mathrm{~nm})$, of PC3 in the Aitken mode $(20-60 \mathrm{~nm}$ at the urban background and rural sites, $20-100 \mathrm{~nm}$ at the roadside), and of PC5 in the accumulation mode $(70-300 \mathrm{~nm})$. Additional components with peak loadings in the accumulation and nucleation mode range were found but are discussed later. The essential outcome is that the single-site analysis is able to reproduce the major features of temporal variability in the PNSD. No information could, however, be retrieved from STA1 on covariations of the PNSD in space.

\subsubsection{Multiple-site principal component analysis}

In addition to several "noise" PCs - explaining the lower part of the variance, STA7 (see Fig. 5a) reveals three "signal" PCs (i.e representing features always present) and four "mixed" PCs (i.e. representing features present in part of the dataset only). The first signal PC represents large-scale PNSDs with a distinct accumulation mode $(>200 \mathrm{~nm})$, and likely refers to regional aerosols. The second and third signal PCs represent PNSDs with aged nucleation (PC2) and Aitken modes (PC3). Their very high spatial correlations are likely to represent new particle formation and growth events. 
Table 3. Principal components in the atmospheric PNSD: Particle size ranges, characteristics, and correlations.

\begin{tabular}{|c|c|c|c|c|c|c|c|}
\hline $\begin{array}{l}\text { Component } \\
\text { description }\end{array}$ & $\begin{array}{l}\text { Size } \\
\text { range }^{2} \\
(\mathrm{~nm})\end{array}$ & Likely sources & $\begin{array}{l}\text { Spatial } \\
\text { scale }\end{array}$ & $\begin{array}{l}\text { Sites } \\
\text { affected }^{3}\end{array}$ & $\begin{array}{l}\text { Temporal scale and } \\
\text { characteristics }\end{array}$ & Intra-site correlations $s^{4,5}$ & $\begin{array}{l}\text { Inter-site } \\
\text { correlations }^{4,5,6}\end{array}$ \\
\hline $\begin{array}{l}\text { fresh, } \\
\text { roadside }\end{array}$ & $<5$ & traffic emissions & local & all & hours & $\begin{array}{l}\text { urban AtM, urban traffic*, } \\
\text { droplet mode* }\end{array}$ & $\begin{array}{l}\mathrm{T}, \mathrm{WS}, \mathrm{LDV}, \mathrm{HDV}, \\
\mathrm{NO}, \mathrm{NO}_{2}, \mathrm{NO}_{\mathrm{x}}, \mathrm{p}^{*}, \\
\mathrm{RH}^{*}\end{array}$ \\
\hline $\begin{array}{l}\text { fresh, } \\
\text { background }\end{array}$ & $<5$ & $\begin{array}{l}\text { photochemically } \\
\text { induced particle } \\
\text { formation and } \\
\text { traffic }\end{array}$ & local & all & hours & $\begin{array}{l}\text { urban AtM, urban traffic*, } \\
\text { droplet mode* }\end{array}$ & $\begin{array}{l}\mathrm{GR}, \mathrm{T}, \mathrm{LDV}, \mathrm{HDV}, \\
\mathrm{SO}_{2}, \mathrm{NO}, \mathrm{NO}_{2}, \mathrm{NO}_{\mathrm{x}}, \\
\mathrm{CO}, \text { benzene, } \mathrm{RH}^{*}\end{array}$ \\
\hline $\begin{array}{l}\text { urban } \\
\text { background }\end{array}$ & $3-15$ & $\begin{array}{l}\text { photochemically } \\
\text { induced particle } \\
\text { formation }\end{array}$ & $\begin{array}{l}\text { local to } \\
\text { urban to } \\
\text { regional }\end{array}$ & $\mathrm{UB}, \mathrm{RB}$ & $\begin{array}{l}\text { hours; } \uparrow \text { at daytime, } \\
\text { midday peak, } \uparrow \text { in } \\
\text { summer }\end{array}$ & $\begin{array}{l}\text { NM-rural, urban AtM, } \\
\text { urban traffic, droplet } \\
\text { mode* }^{*} \text { nucleation- } \\
\text { traffic* }^{*} \text {, aged nucleation* }\end{array}$ & $\begin{array}{l}\mathrm{GR}, \mathrm{T}, \mathrm{MLH}, \mathrm{WS}, \\
\mathrm{WD}, \mathrm{SO}_{2}, \mathrm{NO}, \mathrm{NO}_{2}, \\
\mathrm{NO}_{\mathrm{x}}, \mathrm{O}_{3}, \text { benzene*, } \\
\mathrm{RH}^{*}\end{array}$ \\
\hline roadside & $4-20$ & $\begin{array}{l}\text { nucleation of } \\
\text { traffic-emitted } \\
\text { gases }\end{array}$ & $\begin{array}{l}\text { local to } \\
\text { urban }\end{array}$ & RS & $\begin{array}{l}\text { hours; } \uparrow \text { at daytime, } \\
\text { three daily peaks, } \\
\text { weekly cycle, } \uparrow \text { in } \\
\text { summer }\end{array}$ & $\begin{array}{l}\text { aged NM, urban traffic, } \\
\text { NM-urban*, NM-rural* }\end{array}$ & $\begin{array}{l}\text { GR, p, T, MLH, WS, } \\
\text { WD, LDV, NO, HDV* }\end{array}$ \\
\hline aged-urban & $10-50$ & $\begin{array}{l}\text { aging NM, traffic } \\
\text { emissions }\end{array}$ & $\begin{array}{l}\text { urban to } \\
\text { regional }\end{array}$ & $\mathrm{UB}, \mathrm{RB}$ & $\begin{array}{l}\text { hours; } \uparrow \text { at daytime, } \\
\text { two daily peaks, } \\
\text { weekly cycle, } \uparrow \text { in } \\
\text { summer }\end{array}$ & $\begin{array}{l}\text { NM-rural, NM-urban*, } \\
\text { urban AtM* }\end{array}$ & $\begin{array}{l}\mathrm{p}, \mathrm{T}, \mathrm{LDV}, \mathrm{O}_{3}, \mathrm{RH}^{*}, \\
\text { benzene*, } \mathrm{NO}_{\mathrm{x}}{ }^{*}\end{array}$ \\
\hline \multicolumn{8}{|c|}{ Aitken mode (AtM) size range: } \\
\hline urban traffic & $30-200$ & traffic emissions & $\begin{array}{l}\text { urban to } \\
\text { regional }\end{array}$ & RS & $\begin{array}{l}\uparrow \text { at daytime, two } \\
\text { daily peaks, weekly } \\
\text { cycle }\end{array}$ & $\begin{array}{l}\text { condensation mode, NM- } \\
\text { traffic, NM-urban, NM- } \\
\text { fresh* NM-aged*, NM- } \\
\text { rural*, urban AtM* }^{*}\end{array}$ & T, LDV, HDV \\
\hline \multicolumn{8}{|c|}{ Accumulation mode (AcM) size range: } \\
\hline continental & $>200$ & $\begin{array}{l}\text { long range trans- } \\
\text { port }\end{array}$ & regional & all & - & NM-urban*, NM-rural* & $\begin{array}{l}\mathrm{GR}, \mathrm{T}, \mathrm{PM}_{10}, \mathrm{WD}, \\
\mathrm{SO}_{2}, \text { benzene, } \mathrm{NO}_{2}, \\
\mathrm{RH}^{*}, \mathrm{WS}^{*}, \mathrm{O}_{3} *\end{array}$ \\
\hline $\begin{array}{l}\text { condensation } \\
\text { mode }\end{array}$ & $90-250$ & $\begin{array}{l}\text { aging of urban } \\
\text { particles, traffic }\end{array}$ & $\begin{array}{l}\text { urban to } \\
\text { regional }\end{array}$ & all & $<1$ day; $\uparrow$ in summer & $\begin{array}{l}\text { droplet mode, urban } \\
\text { traffic }\end{array}$ & $\begin{array}{l}\mathrm{GR}, \mathrm{P}, \mathrm{T}, \mathrm{WD}, \mathrm{O}_{3}, \\
\text { benzene", } \mathrm{NO}_{\mathrm{x}}{ }^{*}, \mathrm{RH}^{*}\end{array}$ \\
\hline droplet mode & $\begin{array}{l}300- \\
800\end{array}$ & $\begin{array}{l}\text { cloud \& fog pro- } \\
\text { cessing }\end{array}$ & regional & all & $>1$ day; $\uparrow$ in winter & nucleation-fresh*, LRT & $\begin{array}{l}\text { RH, WS, WD, LDV, } \\
\text { HDV, GR*, T* }\end{array}$ \\
\hline
\end{tabular}

${ }^{1} \mathrm{NM}$ : nucleation mode, AtM: Aitken mode, AcM: accumulation mode. ${ }^{2}$ The modal size range was defined as the area around the peak in the curve of the factor loading as a function of particle size, delimited by the positions of $2 / 3$ of the peak value on both sites. ${ }^{3} \mathrm{RB}$ : rural background, UB: urban background, RS: roadside. ${ }^{4}$ Only correlations $>0.3$ are shown. ${ }^{5}$ The asteriks $(*)$ indicates anti correlation. ${ }^{6} \mathrm{RH}$ : relative humidity, T: temperature, GR: global radiation, p: pressure, WS: wind speed, WD: wind direction, LDV: light duty vehicles, HDV: heavy duty vehicles, LRT: long range transport, MLH: mixing layer height. 

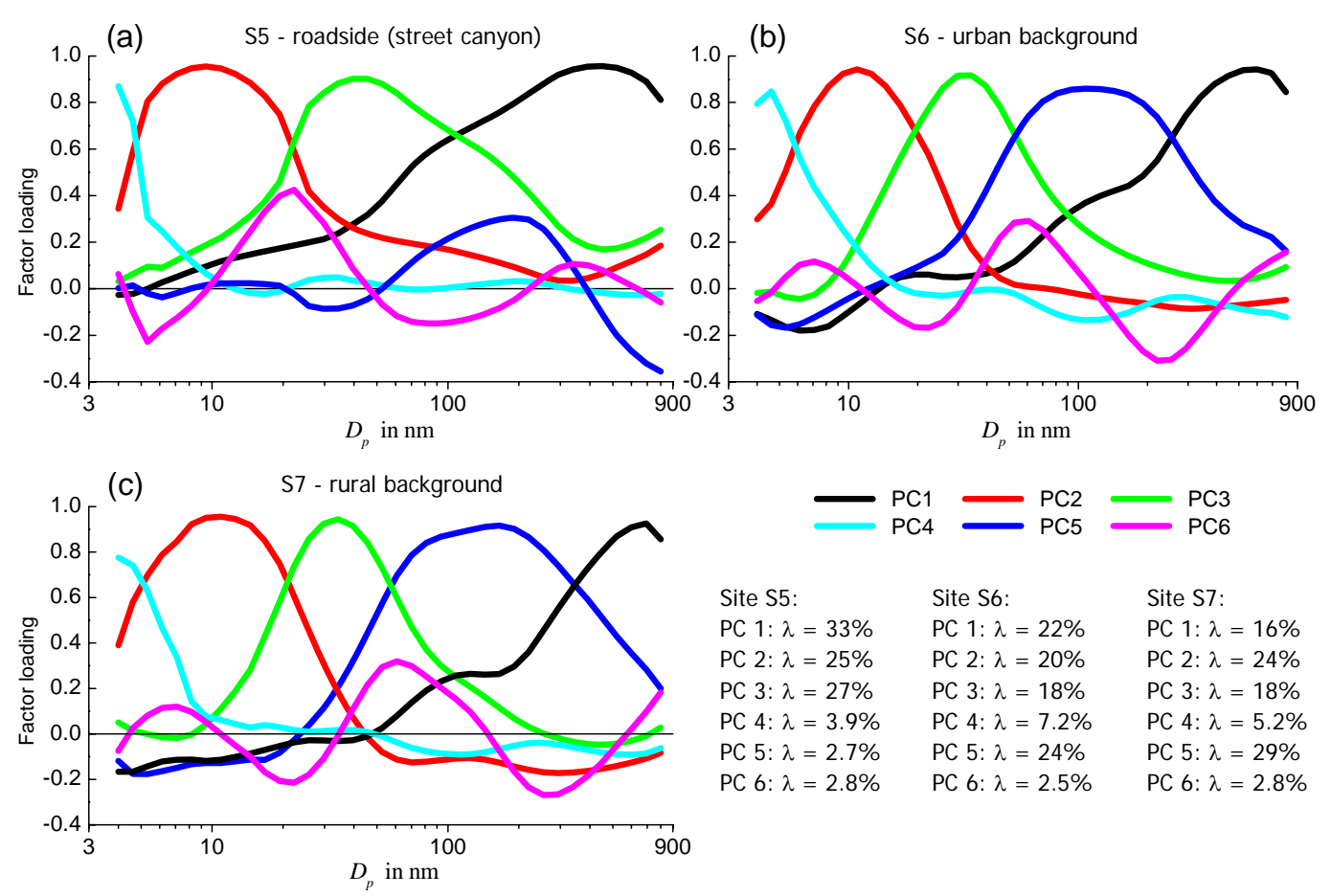

Fig. 4. Principal component results from STA1 (long-term experiment) for three different sites: (a) S5 (roadside), (b) S6 (urban background), and (c) S7 (rural). The variance $\lambda$ explained by each component is indicated as a relative percentage of the total variance.

Two similar mixed PCs (PC4 and PC5) show then a very wide Aitken mode characteristic of the two traffic sites. Several findings strongly indicate urban traffic to be represented by both PC4 and PC5. First, the statistical analysis at single sites only cannot fully recognize this aerosol population - the particle size range of PC3 at the site S5 in Fig. 4 is different from the wider particle size range of both PC4 and PC5 in Fig. 5a. Second, this aerosol population is highly correlated with traffic flows (Table 3), is more evident during working days (Fig. 8) and at roadside sites (PC4 and PC5 in Fig. 5a), but is still relevant also at background sites (Fig. 5a and Fig. 7a). We attribute the difference found between the two sites to a different siting of the two sampling inlets. Despite the fact that both the traffic sites (S3 and S5) are equally representative of roadside conditions, some dissimilarity may be noted: the sample inlet height (10 and $6 \mathrm{~m}$, respectively, Table 1) and the orientation of the two sample inlets with respect to the wind direction. These two differences could have induced two types of inhomogenities in the results of the statistical analysis, which probably resulted in two different principal components at the two traffic sites with the same meaning. The different sample inlet heights could have resulted in different correlations between Aitken and nucleation mode particles - the difference between PC4 and PC5 in Fig. 5a is in the nucleation mode loadings, probably due to a different variability with height of the nucleation mode with respect to the Aitken mode. The different sample inlet orientations in the street-canyons could have gener- ated a temporal shift between the two measurements at the two traffic sites - when the sample inlets were under different conditions in the street-canyon (i.e., downwind/leeward) with respect to both local and urban traffic emissions.

Notably, no significant difference is found when the rural site is not included in the STA (Fig. 5a). The three signal PCs and the two mixed PCs before mentioned are still the same indeed, and changes are only found in the noise PCs. This result implies the spatial scale of the before mentioned signal and mixed PCs to be as big as the all study area.

On the other hand, STA4 (Fig. 5c) showed, in general, similar signal and mixed PCs related to the accumulation, Aitken, and nucleation modes. However, the wider size range of the measurements (cf. Table 3) produced apparently much more complex results - two further PCs in the Aitken and accumulation mode size range, and an even more complex nucleation mode. This fact is better discussed in the following paragraph.

\subsubsection{Statistical components in the long-term data set}

STA3 (Table 3) reveals three "signal" PCs (Fig. 5d) with modes in the size range (Table 3) of 300-800 nm (PC1), 90$250 \mathrm{~nm}$ (PC3), 4-20 nm (PC2 - we will call it "traffic" type since it loads highly at the roadside). An additional signal component (PC8, 30-200 nm) is found, quite similar to the before mentioned PC4 and PC5 of STA7. Further "mixed" PCs in the nucleation mode range have higher loadings at the 

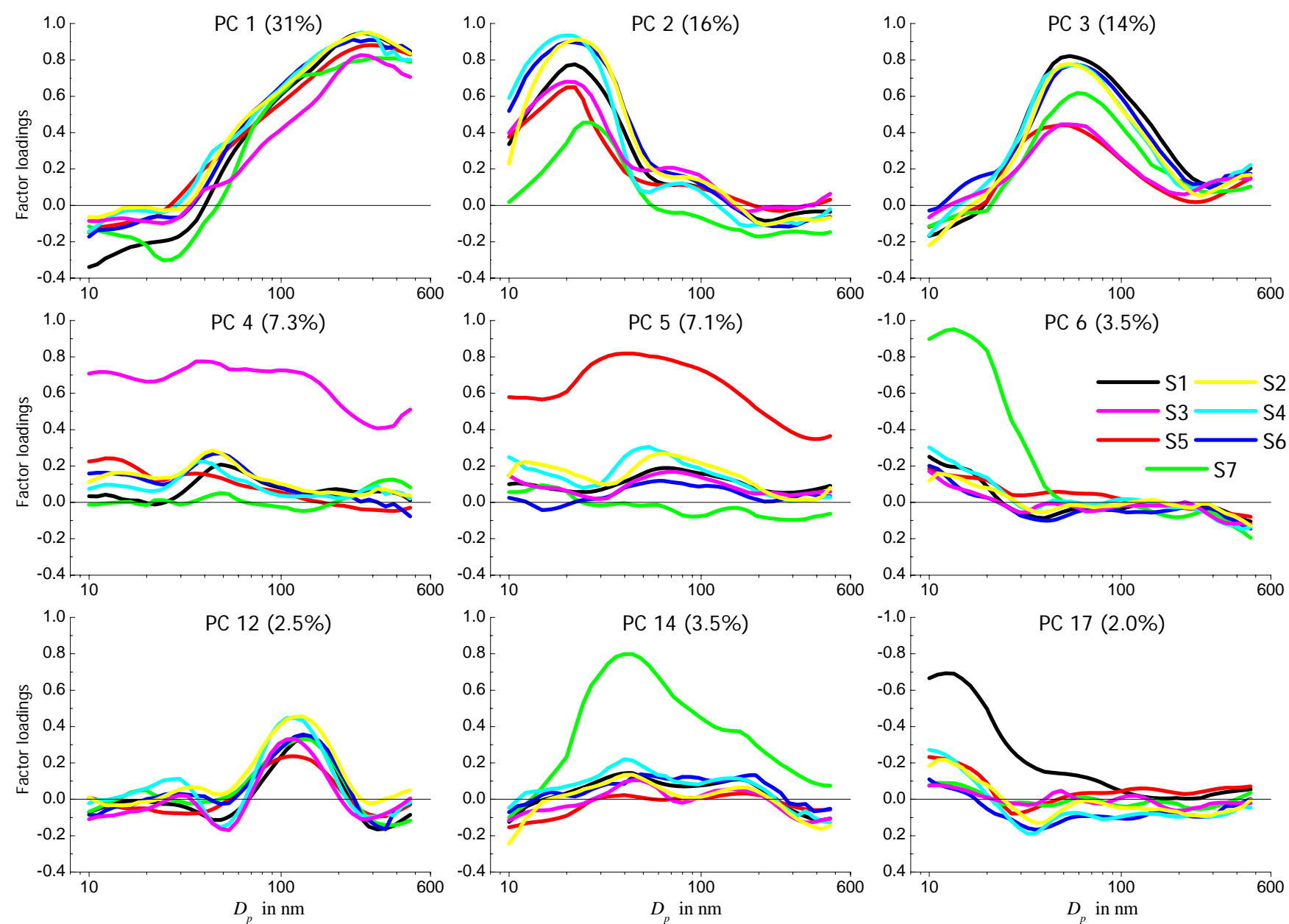

Fig. 5. (a) Factor loadings of the nine most significant principal components (PC) using concurrent size distribution data from seven observation sites (STA7 in Table 2). Only those PCs are shown whose variance exceeds $2.0 \%$ of the total variance in the data set. The variance $\lambda$ is given for each PC as both eigenvalue and relative percentage. (The number of components and the $2.0 \%$ threshold result from the application of the Kaiser and Scree plot criteria.)

rural (PC4, 5-20 nm) and the urban background sites (PC6, $3-15 \mathrm{~nm})$.

To put these findings into perspective, we compared the results of the various STAs: In STA1, the nucleation mode PC2 is a signal PC at all of the sites (Fig. 4); however, only at the roadside PC2 of STA1 exhibits also a correlation with bigger particles up to $100 \mathrm{~nm}$ - similarly to PC2 of STA3 (Fig. 5d). Moreover, a PC4 with mode diameter $<5 \mathrm{~nm}$ appears in all of the STA1; however, because of its low variance no related PC is extracted by the multi-site STA3. Remarkably, the PC4 with the highest variance is extracted by STA1 at the urban background site. As well, PC6 of STA3 (Fig. 5d), which mainly loads at the urban background site (we will call it "urban" type), has the lowest mode diameter. We will discuss this point later as indications of either different nucleation processes or nucleation processes with low correlations in space.
In the Aitken mode range, STA3 extracts three mixed PCs (PC5, PC13 and PC7, Fig. 5d). Both PC5 and PC13 have higher loadings at the urban background sites ("urban Aitken"), but the mode of PC13 is shifted towards larger values $(30-90 \mathrm{~nm})$ - same as the signal PC3 of STA4, STA6, and STA7 (Fig. 5a). PC7 of STA3 has instead higher loadings at the rural site ("rural Aitken") with an smaller mode diameter $(20-70 \mathrm{~nm})$ - as PC8 of STA4 and PC14 of STA7.

In the accumulation mode, the two signal PC1 and PC3 of STA3 (Fig. 5d) are probably connected with the "droplet mode" (John et al., 1990; Meng and Seinfield, 1994) and the "condensation mode" (Seinfeld and Pandis, 2006). Contrary to $\mathrm{PC} 1$, which has the highest spatial correlation, the spatial scale of PC3 depends on the distance from traffic sources. The larger the distance, the higher the loadings. Interestingly, the Aitken and accumulation mode PC1, PC3 and PC5 of STA1 (Fig. 4) are clearly separated only at the non-traffic 

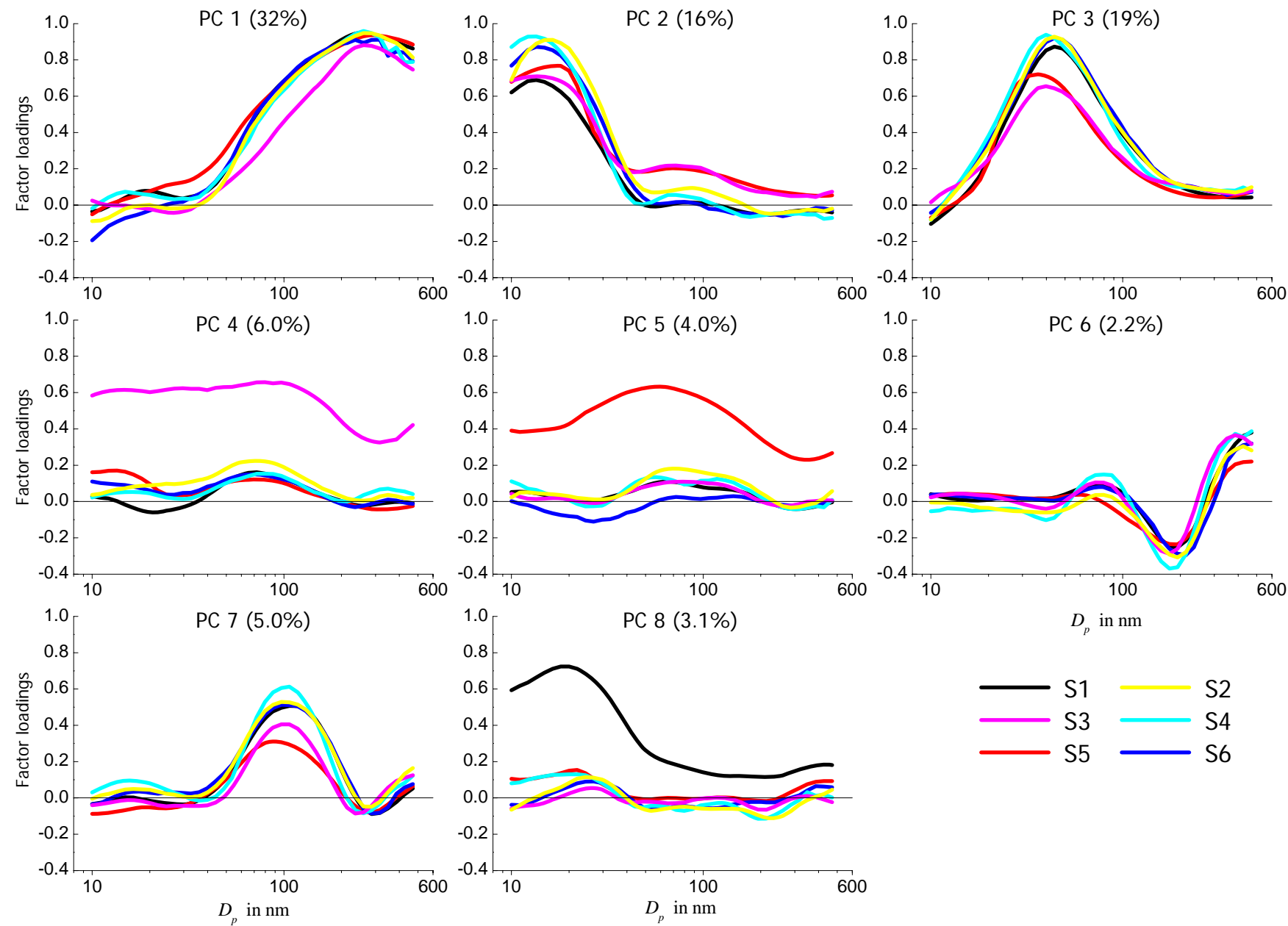

Fig. 5. (b) Factor loadings of the eight most significant principal components (PC) using concurrent size distribution data from six observation sites (STA6 in Table 2).

sites (note that PC5 is not a signal PC at the site No.5). It is probably PC8 of STA3 (Fig. 5d) which explains this difference. PC8 correlates not only 30-200 nm particles at the traffic sites, but also $80-100 \mathrm{~nm}$ particles at the urban and rural background sites. Hence, PC8 seems to be a urban-scale component (we will call it "urban traffic"), rather than local traffic emissions better represented by PC3 of the roadside STA1 (Fig. 4).

\subsection{Size distribution components: temporal behaviour and correlations}

\subsubsection{Temporal cycles}

A general observation was that the presence of high scores was limited to a couple of hours for all nucleation PCs, in the order of several hours for the Aitken, and to days for the accumulation mode PCs. Weekly cycles may be seen for the all PCs with modes below $30 \mathrm{~nm}$ (PC2, PC4, PC6, PC5) and for the "urban traffic" PC8 (Fig. 6). This suggests common traffic source dependance.

All UFP-related PCs, including the "condensation mode" PC3, have both diurnal and seasonal cycles (Table 3). The scores are always higher in summer but for the droplet mode, the long-range transport, and the urban traffic $\mathrm{PC} 8$; nucleation (PC2, PC4, PC6) and condensation (PC3) mode PCs have generally higher scores at daytime, and Aitken mode PCs (PC5, PC7, PC13) in the late evening/early morning or the night-time. This probably reveals the relative importance of photochemically induced factors.

\subsubsection{Inter-correlation}

The consecutive STAc (cf. Sect. 3) calculated for all STAs gave similar results in terms of inter-correlations with meteorological and air pollution variables, as well as intracorrelation between PC scores (see Sect. 4.3.3). Table 3 lists these correlations. Meteorological variations alone showed very weak correlations with the extracted PCs. 

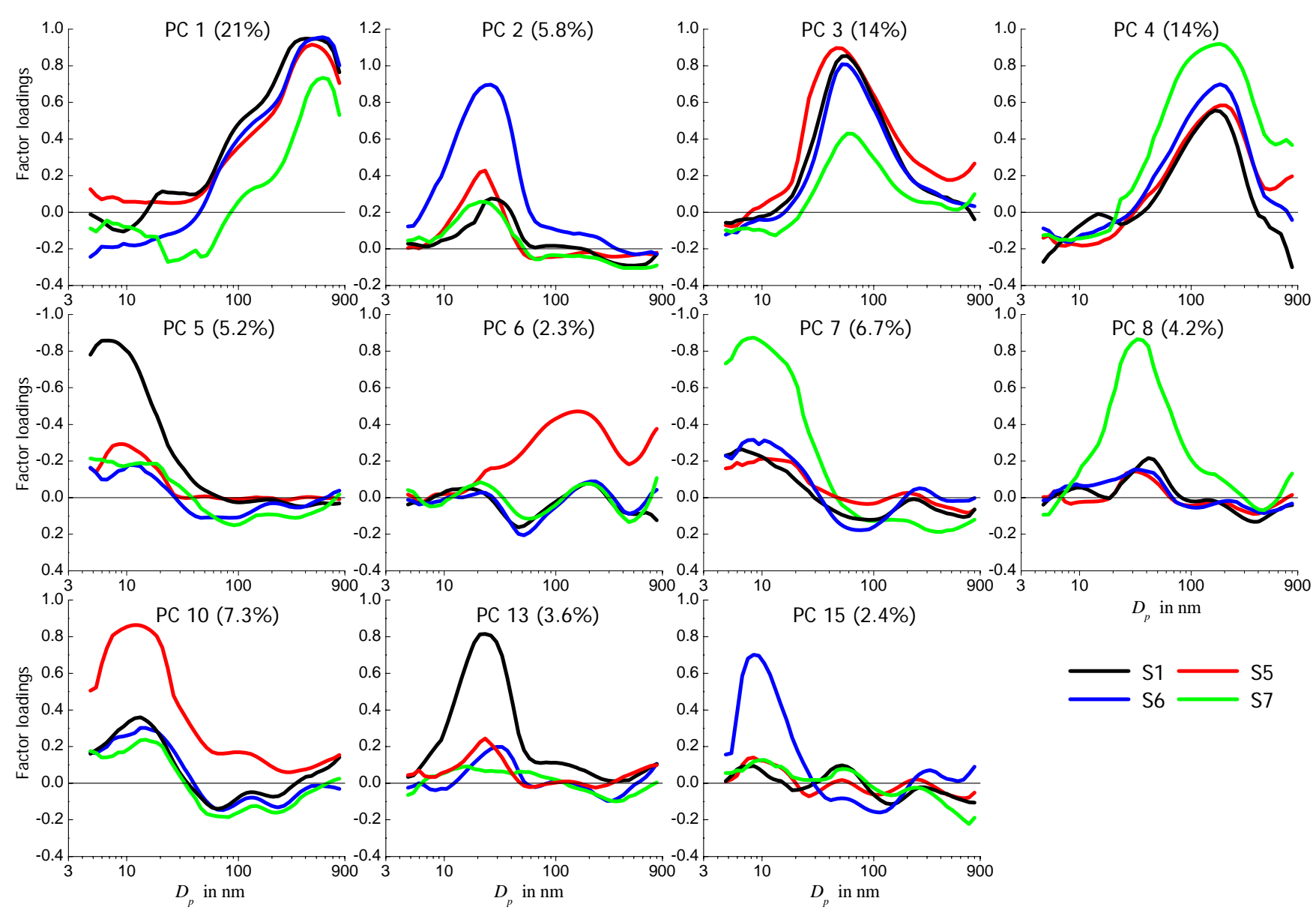

Fig. 5. (c) Factor loadings of the 11 most significant principal components (PC) using concurrent size distribution data from four observation sites (STA4 in Table 2).

However, remarkable inter correlations were found in connection with air pollutants.

Notably, of all the investigated parameters only $\mathrm{PM}_{10}$ has no more than one significant correlation. It is with the accumulation mode PC1 of STA7 (Fig. 5d), and with $\mathrm{SO}_{2}$ and benzene concentrations, suggesting this $\mathrm{PC} 1$ to represent long-range transport particles. This finding indicates extremely different behaviours of $\mathrm{PM}_{10}$ and UFPs.

Oppositely, the relative humidity seems correlate with all of the retained PCs. The correlation with the droplet mode $\mathrm{PC}$ is always positive and quite considerable. The anticorrelations with the UFP-related PCs are, instead, perhaps connected with global radiation, temperature, and ozone. At daytime, for higher light-duty vehicle flows, an interesting time correlation at the background sites was revealed between nucleation mode PCs (inverse correlation), Aitken and condensation mode PCs (direct correlation), ozone (direct correlation), and benzene and $\mathrm{NO}_{\mathrm{x}}$ (inverse correlation) (cf. Table 3).

The results also indicate time correlation between the measured $\mathrm{SO}_{2}$ concentrations and the nucleation mode PCs at the urban background sites (cf. Table 3). It should be perhaps noted as this correlation was probably masked by the fact that higher $\mathrm{SO}_{2}$ concentrations at daytime occurred during two different situations of high pressure: long-range transport due to winds from E/NE, and urban plumes with southwesterly winds. Only the second case was not correlated with bigger particles. For the first case, a higher condensation sink can be expected, and thus a much lower or no nucleation at all.

It should be noted that UFPs were always inter-correlated at the traffic sites. In STA3 (Fig. 5d), in addition to the high correlation with PC8, traffic flows correlate directly with the the traffic- and urban-type nucleation PC2 and PC6, and the condensation mode PC3 during the rush hours, and inversely with the urban Aitken mode PC13 and rural type nucleation PC4. The correlation with the traffic-type nucleation PC2 is somehow interesting. In STA1 (Fig. 4) it is the PC4 (mode $<5 \mathrm{~nm}$ ) that only correlates with traffic flows and (upwards) vertical wind speeds - PC2 also correlates with other meteorological parameter. PC2 increases together with traffic flows, but with rates of increase anti-correlated with it - the 

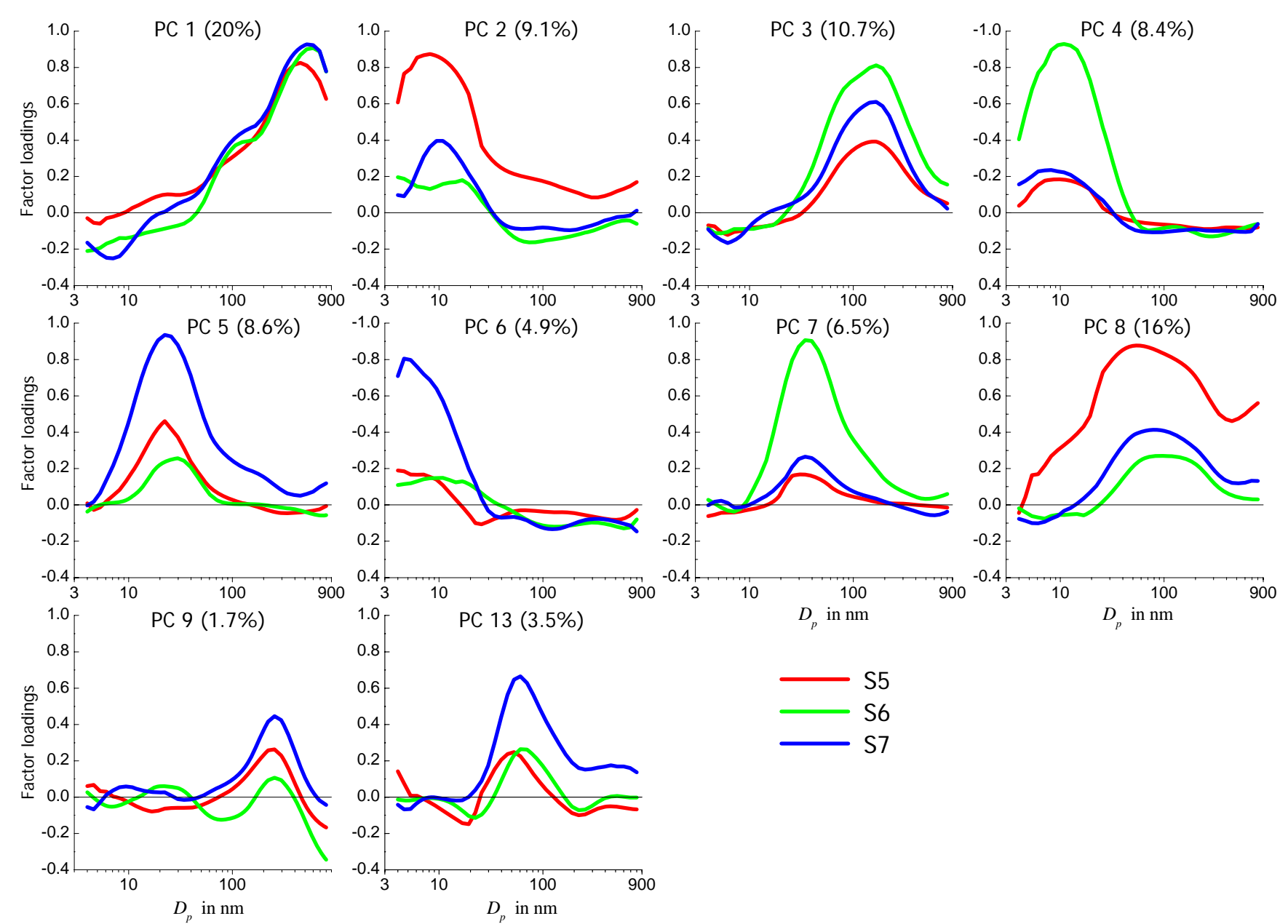
00

Fig. 5. (d) Factor loadings of the 10 most significant principal components (PC) using long-term size distribution data (2 years) from three observation sites (STA3 in Table 2).

correlation being direct with LDV, and inverse with HDV at daytime. This point will be later discussed as a possible evidence that only PC4 (mode $<5 \mathrm{~nm}$ ) of STA1 represents traffic emitted particles.

\subsubsection{Intra-correlation}

The above introduced inter-correlations were always quite weak, and surely weaker than the intra-correlations among the PC scores themselves (according to STAc, cf. Table 3). These time correlations were always notably higher than 0.5 . As a general finding, the highest scores of fresh, aged nucleation and Aitken mode PCs followed each other in time, and were all strongly anti-correlated with the scores of the larger particles. Interestingly, these relations were more clear during large-scale events of new particle formation and growth (for lower scores of the accumulation mode and urban traffic PCs). It is perhaps worth noting as that the "urban traffic" PCs (e.g., PC8 in STA3) correlated with the other PCs in a way similar to what previously discussed for traffic flows.

\subsection{Signature size distributions}

"Signature size distributions" were calculated on the basis of the PCA coefficients, and are displayed in Fig. 7a. The "Signature size distributions" are represented by the unstandardised/normalised coefficients extracted by the Principal Component Analysis calculated in terms of the correlation matrix. We decided to calculate the PCA in terms of the correlation matrix in order the coefficients $\left(\alpha_{k, j}\right)$ to be directly linked to - and to represent - the correlations between the original variables, i.e. the aerosol particle concentrations, and the PCs, i.e. the particular aerosol populations. Therefore, the coefficients would represent the relative weight of the aerosol particle concentrations in each particular aerosol population. We interpreted this as signature size distributions.

To compare more easily the values of the coefficients to the aerosol particle concentrations, we reported in Fig. 7a the coefficients $\alpha_{k, j}$ after their un-standardisation with respect to 



Fig. 6. Diurnal cycles of the principal component scores calculated in STA3 (see Table 3). Median values across the entire data set are compared against weekday and weekend average values.

mean and standard deviation $\left(\alpha_{k, j} \cdot \sigma+\mu\right)$, and after their un-log-normalization $\left(10^{\alpha_{k, j} \cdot \sigma+\mu}\right)$. (This is the inverse procedure of data normalization and standardization according to we calculated the loadings reported in Fig. 5a). One might note that also the loadings $\left(\frac{\alpha_{k, j}}{\sqrt{\lambda_{k}}}\right)$ have a meaning similar to the coefficients. However, the loadings are scaled by the amount of variance $\left(\lambda_{k}\right)$ explained by each PC. They can, thus, be misleading in representing the particle size distributions.

Figure 7a covers three analyses, STA7, STA4 and STA3. During the intensive spatial experiment in spring time 2005 - analysed by STA7, the signature PNSDs at urban background sites are dominated by long-range transport ( $\mathrm{PC} 1$ in Fig. 7a) and new particle formation and subsequent growth events (PC2 and PC3 in Fig. 7a). Particles in the nucleation mode range at the traffic sites S3 and S5 are naturally influenced by direct local emissions as well (PC4 and PC5 in Fig. 7a).

It is interesting that the nucleation mode component PC2 in Fig. 7a shows a very similar size-dependent profile across all sites, whether urban background or roadside. It has therefore been a conclusion that $\mathrm{PC} 2$ represents a size distribution component that is spatially homogeneous. We assume that this particle component with a concentration maximum just below $20 \mathrm{~nm}$ has its origin, in part, from direct traffic emissions present over the whole city, which are mixed downwind the sources into the urban canopy layer and, secondly, from gas-phase nucleation and subsequent growth processes across the whole city as well. Within STA7 it was not possible to distinguish these two likely processes due to the limited size range of the data, starting only at $10 \mathrm{~nm}$ diameter, and maybe to the limited duration of this particular data set. It seems that particles originating from both processes overlap in the size spectrum of that component and, owing to the mixing processes in the urban boundary layer, these processes cannot be distinguished any more at true urban background site, i.e. sufficiently downwind of the traffic sources themselves.

At the rural site, new particle formation and related particle aging (PC6 and PC14 of STA7) have a more important effect than in the urban area. A condensation mode (PC3 of STA4, cf. Fig. 5c) is clearly an other important factor particularly at the background sites (Fig. 7b), where its effect is probably not masked by the local traffic emissions. Significant variations are still produced in the droplet mode 

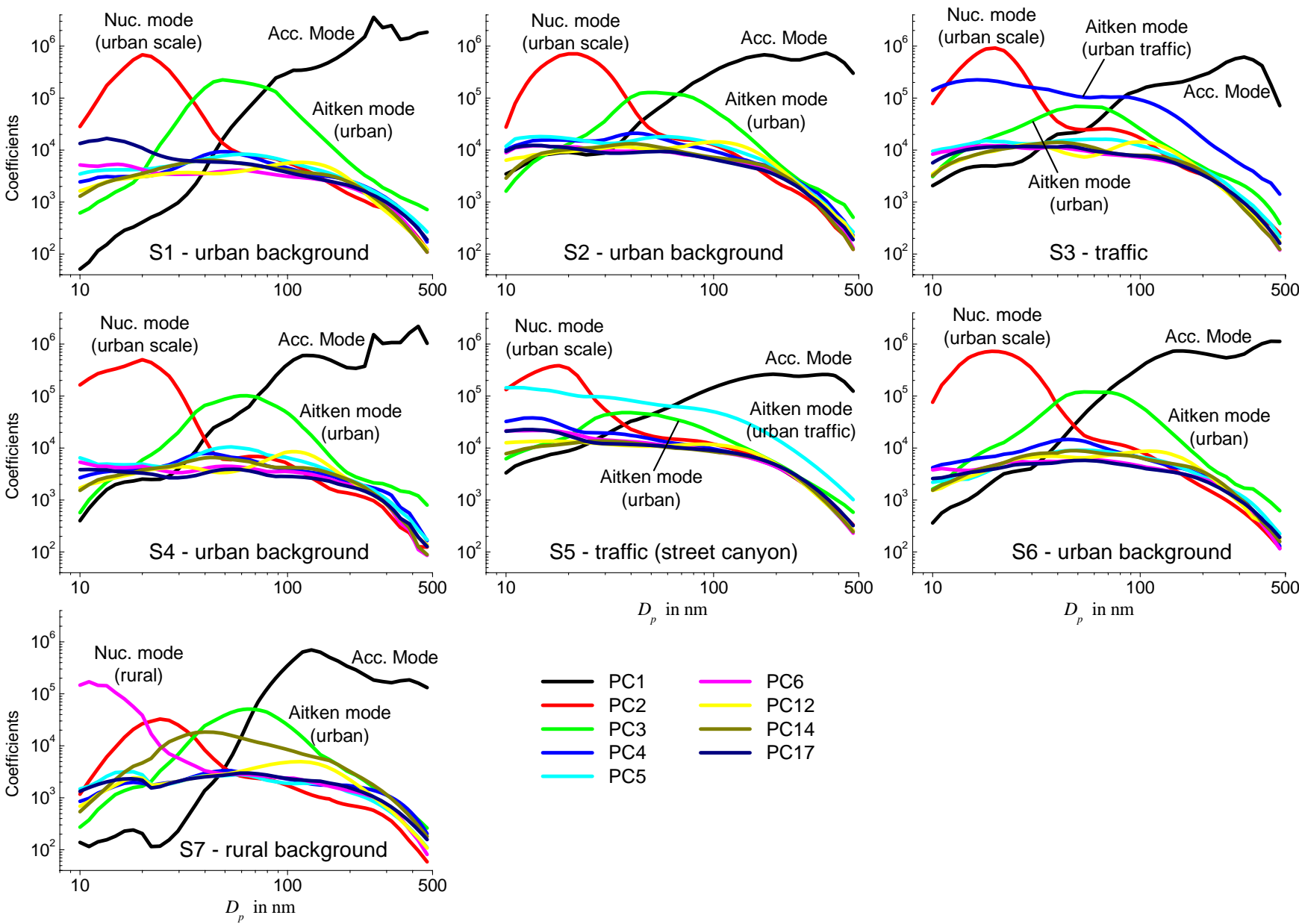

Fig. 7. (a) Signature particle size distributions in STA7 calculated according to the principal component coefficients (cf. Table 3).

(PC1 of STA4). When considering the long-term experiment (Fig. 7c), the new particle formation at the rural site (PC4 of STA3, Fig. 5d), and the accumulation mode particles (both droplet and condensation mode PC1 and PC3 of STA3) still dominate the PNSD. However, "urban traffic" (PC8 of STA3) appears to be more relevant than during the spring campaign, and produces noteworthy variations even at the rural site. Aged nucleation mode particles considerably affect the PNSDs at both the urban and rural background sites (PC5 and PC7 of STA3), whilst fresh nucleation mode particles reveal very peculiar signatures, which will be discussed in the following section.

\section{Discussion}

\subsection{PCA: What can it provide? What does it mean?}

Given sufficient data, PCA is theoretically the optimal linear scheme for compressing (in terms of least mean square error) a set of high-dimensional vectors into a set of lowdimensional vectors, thereby allowing to reconstruct the original set (Mulaik, 1972; Morrison, 1976; Gnanadesikan, 1977). However, the results provided by PCA are limited by the assumptions made during the process: linearity of the original variables, orthogonality of the principal components, the statistical importance of mean, standard deviation and correlation, and the assumption that large variances contain relevant dynamic information on the system.

On the one hand, the last assumption implies that only if the observed data have a high signal-to-noise ratio, the larger variance PCs correspond to interesting dynamics and the lower ones to noise. By making use of both the Kaiser and scree plot criteria, we retained only the PCs representing critical features in the data set - the higher variance or "signal" PCs, and events that happened in a relevant portion of the data set, the "mixed" PCs. Rare and/or local features are not within the scope of our analysis: "Noise" PCs are not expected to represent explain long-term and large-scale tendencies in the variability of the PNSD.

On the other hand, each PC extracted by the multi-site PCA represents an independent statistical deviation of the PNSD from its average value both, in space and time. This 
F. Costabile et al.: Principal components of particle size distributions
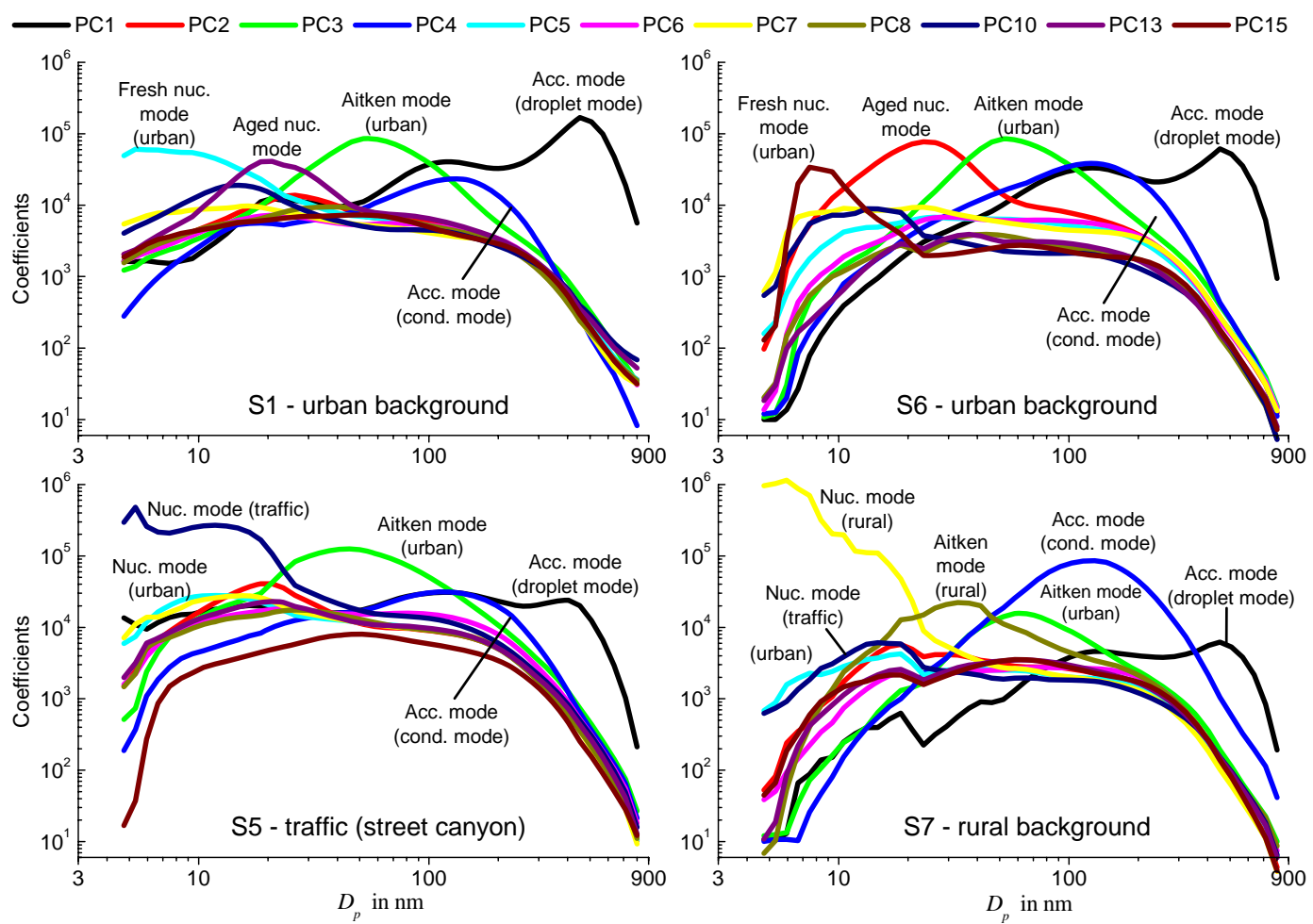

Fig. 7. (b) Signature particle size distributions in STA4 calculated according to the principal component coefficients (cf. Table 3 ).
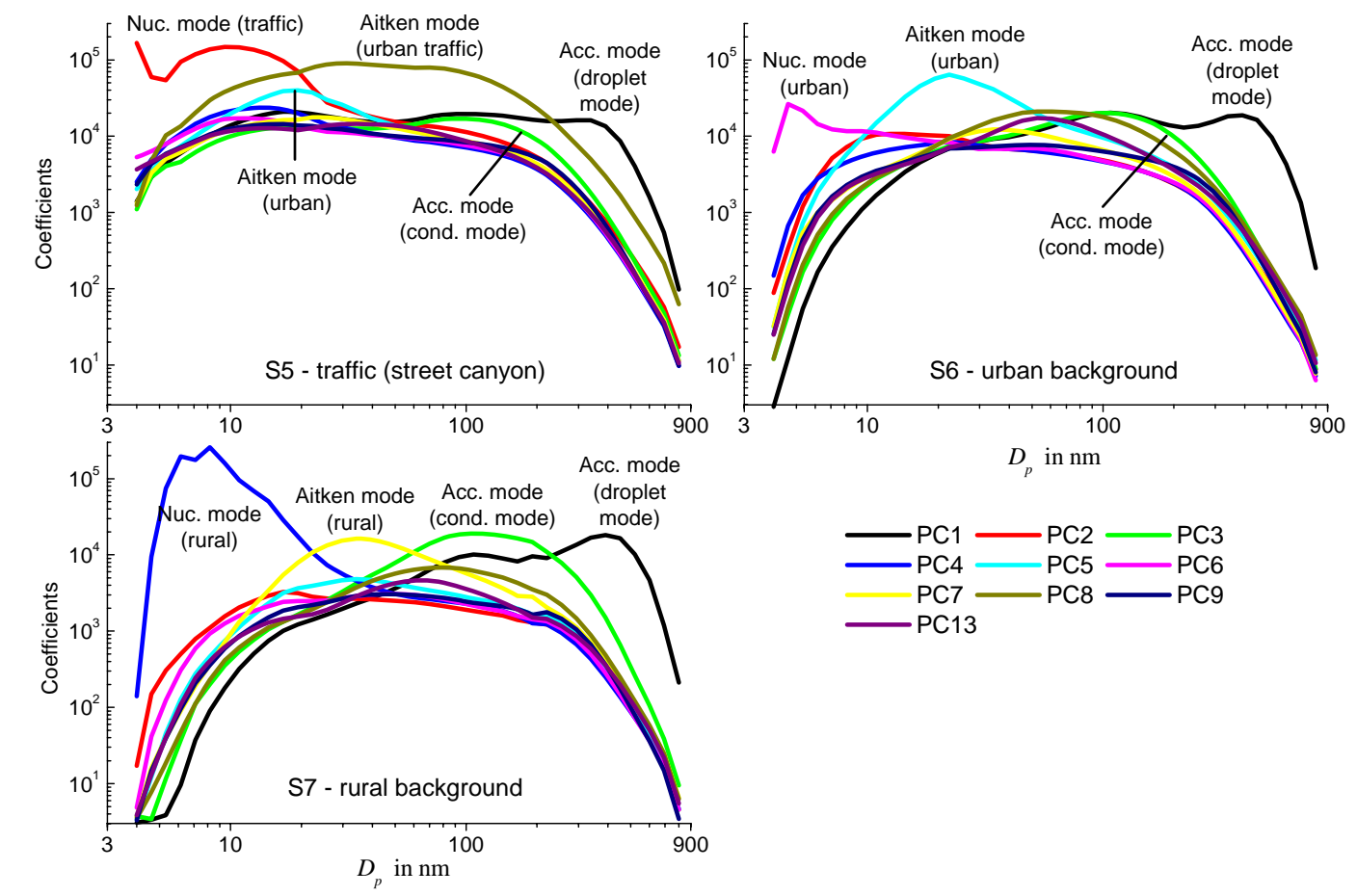

Fig. 7. (c) Signature particle size distributions in STA3 calculated according to the principal component coefficients (cf. Table 3 ). 
deviation was found to be uniquely characterised by a higher statistical variance in a particular size range (mode). (This was probably also influenced by the calculation of loadings in terms of correlations.) Hence, each PC-discriminating factor is probably linked to a common process, which correlates both, in space and time, distinctive PNSD "states". In the single-site STA1, the word "state" is likely to be characterised as a temporal variability in the PNSD (cf. Fig. 2 and Sect. 4.1). This agrees with earlier definitions of a "measurement variability", used to understand life-times of particles (Junge, 1974; Jobson et al., 1998), where PNSD "states" would represent "typical" size distributions (Tunved et al., 2004), or sources (Chan and Mozurkewich, 2007b).

In this work, however, the multi-site PCA considers spatial and temporal correlations simultaneously. Even if the different PCs are not Lagrangian in the sense that a higher PC (here: relating to concentrations at bigger diameters) always follows a lower PC in time, the analysis of the states represented by these PCs help to understand how the different aerosol aging processes are related to each other in a Lagrangian perspective. With this in mind, a deeper discussion of the results is provided in the followings.

\subsection{Spatio-temporal variability of the size distribution}

The spatio-temporal variability of PNSD in the urban and suburban atmosphere of Leipzig was found to be a complex issue. Great variations were found in the PNSD between different sites with the distance to traffic sources being the main dependency. When examining the Pearson rank correlation coefficients for the PNSD between different sites we found the highest correlations $(0.85-0.95)$ for diameters above $100 \mathrm{~nm}$ (i.e. in the accumulation mode), and between similar urban background sites. The lowest correlation coefficients $(0.2-0.3)$ occurred below $20 \mathrm{~nm}$ (i.e. in the nucleation mode) between rural and traffic sites. These findings are not entirely new, but have been observed in several recent experimental studies on the same subject (e.g., Wehner et al., 2002; Ketzel et al., 2004; Hussein et al., 2005; Tuch et al., 2006; Puustinen et al., 2007; Mejia et al., 2008).

Several local-scale but also large-scale factors could be identified in the PNSD observations in Leipzig (Sect. 4). Importantly, these independent statistical factors seem to be cover not only the accumulation mode, but also the Aitken and nucleation mode size ranges. The Tables $4 \mathrm{a}-\mathrm{d}$ place the size distribution factors of this work with particle modes established in the numerous previous studies on urban aerosols. In the following we discuss the characteristics of these factors in more detail, and draw connections to the particle modes established in the literature.

\subsubsection{Statistical factors in the accumulation mode range}

The statistical factor encompassing the highest variance in the overall data set resides in the accumulation mode (PC1 in each of STA7, STA4 and STA3). Meanwhile this factor represents that with the lowest spatial variation. High temporal and spatial homogeneity imply a long life-time of these particles, which can be explained by the low aerosol dynamical progression rates of accumulation mode particles, including coagulation and sedimentation (Hinds, 1999; Seinfeld and Pandis, 2006). As a consequence, wet deposition tends to be the critical limiting factor for the life-time of continental accumulation mode particles (Andronache, 2004).

An interesting because somewhat unexpected result was the separation of the variance in the accumulation mode into two distinct factors (PC1 and PC3 in STA3; cf. Fig. 5a). We conclude that these two factors correspond to two aerosol particle populations identified in the literature before, the "condensation mode" (Seinfeld and Pandis, 2006), i.e. accumulation mode particles containing aged secondary aerosol and also direct anthropogenic emissions, and the "droplet mode" (John et al., 1990; Meng and Seinfield, 1994), i.e. particles that underwent fog or cloud activation and increased in size by liquid phase processes.

Notably, the spatial and temporal variability of the droplet mode (centered around $D_{p}=400 \mathrm{~nm}$ ) is lower than that of the condensation mode (centered around $150 \mathrm{~nm}$ ). Moreover, the droplet accumulation mode is the aerosol factor which is most homogeneous in space and time. The droplet mode was correlated with high relative humidity (Table 3 ); we therefore interpret this mode as being controlled by the large-scale synoptic weather situation because humid air masses have the greatest potential for cloud activation which is apparently needed to produce this mode (Hering and Friedlander, 1982).

In contrast to the droplet mode, the condensation mode state had the higher factor loadings the farther the site was from traffic sources. Positive correlations occurred with temperature, global radiation, and ozone, but not with $\mathrm{NO}_{\mathrm{x}}$ (Table 3). Consistent with the observations of McFiggans et al. (2005), the condensation mode state correlated with $\mathrm{CO}$ and benzene, which are good markers for traffic-related emissions. Mass spectrometric analyzes have frequently identified a mass mode composed mainly of organic material at diameters of about 100-200 nm at observation sites affected by fresh pollution or urban air masses (Jimenez et al., 2003; Drewnick et al., 2004; McFiggans et al., 2005), and we conclude these author's observations correspond to the "condensation mode" identified in our analysis. An immediate consequence would be that the condensation mode part of the accumulation mode represents not only long-range transported aerosol but is also influenced by primary emissions and secondary aerosol formation within the urban atmosphere. Literature evidence on the various accumulation modes is compiled in Table $4 \mathrm{a}$.

\subsubsection{Statistical factors in the Aitken mode range}

Aitken mode particles (around 30-90 nm) were represented by more than one PC, and included factors representing 
Table 4a. Literature evidence on atmospheric particle modes, with emphasis on urban environments: accumulation mode.

\begin{tabular}{|c|c|c|c|c|}
\hline$D_{p}(\mathrm{~nm})$ & Description & Method $^{1}$ & $\begin{array}{l}\text { Site } \\
\text { type }^{2}\end{array}$ & Study \\
\hline \multicolumn{5}{|c|}{ Accumulation mode I } \\
\hline 250 & Traffic influenced aerosol & Mode of volume size distribution & UB & Hidy (1975) \\
\hline 200 & Suburban aerosol & Mode of volume size distribution & $\mathrm{RB}$ & Meszaros (1977) \\
\hline 200 & Suburban background aerosol & Mode of PNSD & $\mathrm{RB}$ & Morawska et al. (1999) \\
\hline 228,384 & Regional pollution & $\begin{array}{l}\text { Lognormal fits of PCA factor load- } \\
\text { ings }\end{array}$ & $\mathrm{RB}$ & $\begin{array}{l}\text { Chan and Mozurkewich } \\
\text { (2007b) }\end{array}$ \\
\hline$>200$ & Long-range transport & Modal size range by multi-site PCA & all & This work \\
\hline \multicolumn{5}{|c|}{ Accumulation mode II } \\
\hline $180-220$ & Condensation mode & $\begin{array}{l}\text { Max in aerodynamic mass distribu- } \\
\text { tion }\end{array}$ & & $\begin{array}{l}\text { Hering and Friedlander } \\
(1982)\end{array}$ \\
\hline 200 & Condensation mode & & & Meng and Seinfield (1994) \\
\hline $171-207$ & Accumulation mode & GMD & $\mathrm{RB}$ & Mäkelä et al. (2000b) \\
\hline $150-250$ & Accumulation mode & $\begin{array}{l}\text { Lognormal fitting }(160-250,150- \\
240,150-210 \mathrm{~nm})\end{array}$ & $\mathrm{RB}$ & Birmili et al. (2001) \\
\hline $180-236$ & Accumulation mode & Lognormal modes & UB & $\begin{array}{l}\text { Wehner and Wiedensohler } \\
\text { (2003) }\end{array}$ \\
\hline ca. 150 & Accumulation mode & GMD of the mode fitting parameters & UB & Hussein et al. (2004) \\
\hline $50-170$ & $\begin{array}{l}\text { Aged air masses not originating directly } \\
\text { from traffic }\end{array}$ & PC mode by PCA & $\mathrm{RS}$ & Janhäll et al. (2004) \\
\hline $100-200$ & Accumulation mode & GMD of PNSD & all & Hussein et al. (2005) \\
\hline $117-163$ & Accumulation mode & Lognormal GMD & UB & Mönkkönen et al. (2005) \\
\hline $110-240$ & - & $\begin{array}{l}\text { Max of moving average correlation } \\
\text { coefficient }\end{array}$ & UB & Gramotnev et al. (2007) \\
\hline 171,178 & Accumulation mode & $\begin{array}{l}\text { Lognormal fits of PCA factor load- } \\
\text { ings }\end{array}$ & UB & $\begin{array}{l}\text { Chan and Mozurkewich } \\
(2007 \mathrm{~b})\end{array}$ \\
\hline $122-321$ & $\begin{array}{l}\text { AcM “1”: sulphuric acid } 21 \% \text {, OC } \\
24.5 \% \text {, EC } 19 \% \text {, mineral dust } 12 \% \text {, sea } \\
\text { salt } 2.5 \% \text {, ammonium nitrate } 21.3 \%\end{array}$ & Max of the PNSD & UB & Pohjola et al. (2007) \\
\hline 100 & Organic aerosol mode & Mode of particle mass distribution & all & Schneider et al. (2008) \\
\hline $100-200$ & Small-mode organics & Mode of mass size distribution & UB & Cubison et al. (2008) \\
\hline 134-208 & Accumulation mode & $\begin{array}{l}\text { Lognormal modal parameters of } \\
\text { PNSD }\end{array}$ & RS, UB & Birmili et al. (2009) \\
\hline $90-250$ & Condensation AcM & Modal size range by multi-site PCA & all & This work \\
\hline \multicolumn{5}{|c|}{ Accumulation mode III } \\
\hline 500 & Background aerosol & Mode of volume size distribution & UB & Hidy (1975) \\
\hline 700 & $\begin{array}{l}\text { Droplet mode, acqueous phase chemi- } \\
\text { cal reactions }\end{array}$ & $\begin{array}{l}\text { Max in aerodynamic mass distribu- } \\
\text { tion }\end{array}$ & & $\begin{array}{l}\text { Hering and Friedlander } \\
(1982)\end{array}$ \\
\hline 700 & Droplet mode from cloud processing & Aerodynamic diameter & & John et al. (1990) \\
\hline 700 & $\begin{array}{l}\text { Droplet mode, activation of condensa- } \\
\text { tion mode, cloud-fog drops, aqueous } \\
\text { phase chemistry }\end{array}$ & Aerodynamic diameter & & Meng and Seinfield (1994) \\
\hline $200-400$ & Background aerosol & Mode of volume size distribution & $\mathrm{RB}$ & Le Canut et al. (1996) \\
\hline $\begin{array}{l}>300,240- \\
470\end{array}$ & $\begin{array}{l}\text { Sea spray or droplet mode. Accumula- } \\
\text { tion mode } 2\end{array}$ & $\begin{array}{lcc}\text { Lognormal } & \text { fitting } & (240-320, \\
280-330, & 280-370, & 280-440, \\
300-470 \mathrm{~nm}) & \end{array}$ & $\mathrm{RB}$ & Birmili et al. (2001) \\
\hline $200-300$ & Accumulation mode & & $\mathrm{RB}$ & Ketzel et al. (2004) \\
\hline $321-1250$ & $\begin{array}{l}\text { AcM “2”: sulphuric acid } 21 \% \text {, OC } \\
24.5 \% \text {, EC } 19 \% \text {, mineral dust } 12 \% \text {, sea } \\
\text { salt } 2.5 \% \text {, ammonium nitrate } 21.3 \%\end{array}$ & Max of the PNSD & UB & Pohjola et al. (2007) \\
\hline $200-400$ & Large-mode organics, total inorganics & Mode of mass size distribution & UB & Cubison et al. (2008) \\
\hline $300-800$ & Droplet AcM & Modal size range by multi-site PCA & all & This work \\
\hline
\end{tabular}

${ }^{1}$ PNSD: particle number size distribution, PC: principal component, PCA: principal component analysis, DGN: geometric number mean size, GMD: geometric mean diameter. ${ }^{2}$ RS: roadside, UB: urban background, RB: regional background. 
Table 4b. Literature evidence on atmospheric particle modes, with emphasis on urban environments: Aitken mode.

\begin{tabular}{|c|c|c|c|c|}
\hline $\begin{array}{l}D_{p} \\
(\mathrm{~nm})\end{array}$ & Description & Method $^{1}$ & $\begin{array}{l}\text { Site } \\
\text { type }^{2}\end{array}$ & Study \\
\hline \multicolumn{5}{|c|}{ Aitken mode I } \\
\hline 62 & Accumulation mode: urban and freeway & Lognormal fits & $\begin{array}{l}\mathrm{UB} \\
\mathrm{RS}\end{array}$ & Whitby (1978) \\
\hline 200 & Traffic influenced aerosol & Mode of volume size distribution & $\mathrm{RS}$ & Morawska et al. (1998) \\
\hline $40-100$ & & & RS & Kittelson et al. (2000) \\
\hline $50-100$ & Decay of freeway emissions & Mode of PNSD & RS,UB & Zhu et al. (2002) \\
\hline $50-200$ & Downwind the highway & Maximum in PNSD & RS & Zhang et al. (2004) \\
\hline $15-60$ & Aitken mode & GMD of highway PNSD & $\mathrm{RS}$ & Hussein et al. (2005) \\
\hline $50-300$ & $\begin{array}{l}\text { Soot aggregates from incomplete combus- } \\
\text { tion }\end{array}$ & Maximum in PNSD & $\mathrm{RS}$ & Imhof et al. (2005) \\
\hline ca. 50 & Emissions from light-duty vehicles & Mode of PNSD & $\mathrm{RS}$ & Yao et al. (2006) \\
\hline 80 & - & $\begin{array}{l}\text { Max of moving average correlation } \\
\text { coefficient }\end{array}$ & UB & Gramotnev et al. (2007) \\
\hline $\begin{array}{l}43.2- \\
122\end{array}$ & $\begin{array}{l}\text { Aitken: OC } 27 \% \text {, EC } 64 \% \text {, mineral dust } \\
7 \% \text {, ammonium sulphate } 2.2 \% \text {, ammo- } \\
\text { nium nitrate } 0.3 \%\end{array}$ & Max of the PNSD & $\mathrm{RS}$ & Pohjola et al. (2007) \\
\hline $53-81$ & Aitken mode & $\begin{array}{l}\text { Lognormal modal parameters of } \\
\text { PNSD }\end{array}$ & $\begin{array}{l}\text { RS, } \\
\text { UB }\end{array}$ & Birmili et al. (2009) \\
\hline $30-200$ & Urban soot AtM & Modal size range by multi-site PCA & RS & This work \\
\hline \multicolumn{5}{|c|}{ Aitken mode II } \\
\hline 54 & Accumulation mode: urban average & Lognormal fits & UB & Whitby (1978) \\
\hline $20-40$ & Nuclei mode of urban-influenced aerosol & Mode of PNSD & UB & Morawska et al. (1999) \\
\hline $39-68$ & - & Lognormal modes & UB & $\begin{array}{l}\text { Wehner and Wiedensohler } \\
(2003)\end{array}$ \\
\hline $\begin{array}{l}43.8- \\
48.1\end{array}$ & Aitken mode & GMD of the mode fitting parameters & UB & Hussein et al. (2004) \\
\hline $30-100$ & $\begin{array}{l}\text { Growing and coagulating of nucleated par- } \\
\text { ticles. Primary particles growing by con- } \\
\text { densation }\end{array}$ & Maximum in PNSD & UB & Stanier et al. (2004) \\
\hline $40-50$ & Aitken mode & Mode of the PNSD & UB & Ketzel et al. (2004) \\
\hline $\begin{array}{l}33.6- \\
60.5\end{array}$ & Aitken mode & Lognormal GMD & UB & Mönkkönen et al. (2005) \\
\hline 55 & 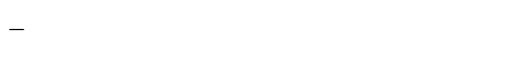 & $\begin{array}{l}\text { Max of moving average correlation } \\
\text { coefficient }\end{array}$ & UB & Gramotnev et al. (2007) \\
\hline $\begin{array}{l}43.2- \\
122\end{array}$ & $\begin{array}{l}\text { Aitken: sulphuric acid } 21 \% \text {, OC } 24.5 \% \text {, } \\
\text { EC } 19 \% \text {, mineral dust } 12 \% \text {, sea salt } 2.5 \% \text {, } \\
\text { ammonium nitrate } 21.3 \%\end{array}$ & Max of the PNSD & UB & Pohjola et al. (2007) \\
\hline $30-90$ & Urban background AtM & Modal size range by multi-site PCA & UB & This work \\
\hline \multicolumn{5}{|c|}{ Aitken mode III) } \\
\hline 76 & Accumulation mode: average background & Lognormal fits & $\mathrm{RB}$ & Whitby (1978) \\
\hline $44-65$ & Aitken mode & GMD & $\mathrm{RB}$ & Mäkelä et al. (2000b) \\
\hline $30-110$ & Aitken mode & $\begin{array}{l}\text { Lognormal fitting }(45-74,60-88,52- \\
85,50-83,48-80 \mathrm{~nm})\end{array}$ & $\mathrm{RB}$ & Birmili et al. (2001) \\
\hline $50-60$ & Aitken mode & Mode of the PNSD & $\mathrm{RB}$ & Ketzel et al. (2004) \\
\hline 25 & & Lognormal mode & $\mathrm{UB}^{3}$ & Hussein et al. (2004) \\
\hline 60 & Aitken mode & & $\mathrm{RB}$ & Laaksonen et al. (2005) \\
\hline $20-70$ & Rural background AtM & Modal size range by multi-site PCA & $\mathrm{RB}$ & This work \\
\hline
\end{tabular}

1 PNSD: particle number size distribution, PC: principal component, PCA: principal component analysis, DGN: geometric number mean size, GMD: geometric mean diameter. ${ }^{2}$ RS: roadside, UB: urban background, RB: regional background. ${ }^{3}$ Observed at UB but assumed to be of regional origin. 
Table 4c. Literature evidence on atmospheric particle modes, with emphasis on urban environments: nucleation mode, part 1.

\begin{tabular}{|c|c|c|c|c|}
\hline $\begin{array}{l}D_{p} \\
(\mathrm{~nm})\end{array}$ & Description & Method $^{1}$ & $\begin{array}{l}\text { Site } \\
\text { type }^{2}\end{array}$ & Study \\
\hline \multicolumn{5}{|c|}{ Nucleation mode I } \\
\hline $3-7$ & Emission from point sources & UCPC/CPC & RS & Alam et al. (2003) \\
\hline 5 & Non-volatile core after thermodenuder & Max in the PNSD & $\mathrm{RS}$ & Rönkkö et al. (2007) \\
\hline $3-7.5$ & $\begin{array}{l}\text { Nucleation } 1 \text { : OC } 90 \% \text {, sulfuric acid } 5 \% \text {, } \\
\text { ammonium sulphate } 5 \%\end{array}$ & Max in the PNSD & $\mathrm{RS}$ & Pohjola et al. (2007) \\
\hline$<5$ & Fresh roadside NM & Modal size range by multisite PCA & $\mathrm{RS}$ & This work \\
\hline \multicolumn{5}{|c|}{ Nucleation mode II } \\
\hline $3-10$ & Collision-controlled nucleation & $\begin{array}{l}\text { Increase in measured and theoretical } \\
\text { PNSD }(3-10 \mathrm{~nm})\end{array}$ & UB & McMurry et al. (2000) \\
\hline $3-8$ & Recently formed particles & PNSD $(3-8 \mathrm{~nm})$ & UB & Williams et al. (2000) \\
\hline $3-9$ & Fresh nucleation mode & Lognormal fit & $\mathrm{RB}$ & Birmili et al. (2001) \\
\hline $3-10$ & $\begin{array}{l}\text { Photochemically driven collision- } \\
\text { controlled nucleation }\end{array}$ & Mode of PNSD & UB & Woo et al. (2001) \\
\hline $3-7$ & $\begin{array}{l}\text { Homogeneous nucleation within the at- } \\
\text { mosphere }\end{array}$ & $\mathrm{UCPC} / \mathrm{CPC}$ & UB & Alam et al. (2003) \\
\hline $3-7.5$ & $\begin{array}{l}\text { Nucleation } 1 \text { : OC } 68 \% \text {, EC } 19 \% \text {, sulfuric } \\
\text { acid } 7 \% \text {, ammonium sulphate } 6 \%\end{array}$ & Max in the PNSD & UB & Pohjola et al. (2007) \\
\hline$<5$ & Fresh urban background NM & Modal size range by multi-site PCA & $\mathrm{UB}, \mathrm{RB}$ & This work \\
\hline \multicolumn{5}{|c|}{ Nucleation mode III } \\
\hline 9,13 & $\begin{array}{l}\text { Nuclei mode: background and local } \\
\text { sources, urban and freeway }\end{array}$ & Lognormal fits & RS, UB & Whitby (1978) \\
\hline $8-13$ & Nuclei mode from diesel engine & Mode of PNSD & RS & Kittelson (1998) \\
\hline $6-25$ & Freeway emissions & Mode of PNSD & $\mathrm{RS}$ & Zhu et al. (2002) \\
\hline$<10$ & Fresh diesel aerosol with nucleation mode & Chasing experiment; mode of PNSD & $\mathrm{RS}$ & Bukowiecki et al. (2002) \\
\hline $7-20$ & Downwind the highway & Maximum in PNSD & $\mathrm{RS}$ & Zhang et al. (2004) \\
\hline $\begin{array}{l}9-12 \\
<15\end{array}$ & Nucleation mode & Lognormal fits, GMD & RS & Hussein et al. (2005) \\
\hline $6-11$ & Nuclei mode of diesel exhaust aerosol & Chasing experiment; mode of PNSD & $\mathrm{RS}$ & Kittelson et al. (2006) \\
\hline ca. 10 & $\begin{array}{l}\text { Emissions from light or heavy duty vehi- } \\
\text { cles }\end{array}$ & Mode of PNSD & $\mathrm{RS}$ & Yao et al. (2006) \\
\hline 9 & Photochemical nucleation & $\begin{array}{l}\text { Lognormal fits of PCA factor load- } \\
\text { ings }\end{array}$ & $\mathrm{RS}$ & $\begin{array}{l}\text { Chan and Mozurkewich } \\
(2007 \mathrm{~b})\end{array}$ \\
\hline $7.5-43$ & $\begin{array}{l}\text { Nucleation 2: OC } 68 \% \text {, EC } 19 \% \text {, sulfuric } \\
\text { acid } 7 \% \text {, ammonium sulphate } 6 \%\end{array}$ & Max of the PNSD & $\mathrm{RS}$ & Pohjola et al. (2007) \\
\hline $4-20$ & Urban roadside $\mathrm{NM}$ & Modal size range by multi-site PCA & RS & This work \\
\hline \multicolumn{5}{|c|}{ Nucleation mode IV } \\
\hline 10 & Transient nuclei mode & Mode of PNSD & UB & Willeke and Whitby (1975) \\
\hline 14 & $\begin{array}{l}\text { Nuclei mode: urban average, background } \\
\text { and aged urban plume }\end{array}$ & Lognormal fits & UB & Whitby (1978) \\
\hline $10-20$ & Urban ambient air with nucleation mode & Mobile lab: mode of PNSD & UB & Bukowiecki et al. (2002) \\
\hline $10-18$ & Nucleation mode & Lognormal modes & UB & $\begin{array}{l}\text { Wehner and Wiedensohler } \\
(2003)\end{array}$ \\
\hline 8.9 & Fresh nucleation mode & GMD of the mode fitting parameters & UB & Hussein et al. (2004) \\
\hline $3-10$ & $\begin{array}{l}\text { nuclei mode particle - marker for nucle- } \\
\text { ation }\end{array}$ & $\begin{array}{l}\text { Increase in the number of } 3-10 \mathrm{~nm} \\
\text { particles }\end{array}$ & UB & Stanier et al. (2004) \\
\hline $\begin{array}{l}4.8- \\
22.8\end{array}$ & $\begin{array}{l}\text { Nucleation mode particles in a highly pol- } \\
\text { luted megacity }\end{array}$ & Lognormal GMD & UB & Mönkkönen et al. (2005) \\
\hline & & & & Stolzenburg et al. (2005) \\
\hline 9.8 & Nucleation mode & Lognormal mode, GMD & UB & Hussein et al. (2005) \\
\hline 9,12 & Photochemical nucleation & $\begin{array}{l}\text { Lognormal fits of PCA factor load- } \\
\text { ings }\end{array}$ & UB & $\begin{array}{l}\text { Chan and Mozurkewich } \\
(2007 \mathrm{~b})\end{array}$ \\
\hline $3-15$ & Urban background NM & Modal size range by multi-site PCA & UB & This work \\
\hline
\end{tabular}

1 PNSD: particle number size distribution, PC: principal component, PCA: principal component analysis, DGN: geometric number mean size, GMD: geometric mean diameter. ${ }^{2}$ RS: roadside, UB: urban background, RB: regional background. 
Table 4d. Literature evidence on atmospheric particle modes, with emphasis on urban environments: nucleation mode, part 2.

\begin{tabular}{|c|c|c|c|c|}
\hline $\begin{array}{l}D_{p} \\
(\mathrm{~nm})\end{array}$ & Description & Method $^{1}$ & $\begin{array}{l}\text { Site } \\
\text { type }^{2}\end{array}$ & Study \\
\hline \multicolumn{5}{|c|}{ Nucleation mode $V$} \\
\hline 15 & Nuclei mode: average background & Lognormal fits & UB & Whitby (1978) \\
\hline $10-17$ & Nucleation mode & GMD & $\mathrm{RB}$ & Mäkelä et al. (2000b) \\
\hline $3-11$ & Freshly formed particles & PNSD during NPF events & $\mathrm{RB}$ & Birmili et al. (2003) \\
\hline 10 & Nucleation mode & Mode of PNSD & $\mathrm{RB}$ & Ketzel et al. (2004) \\
\hline 14.3 & Nucleation mode & $\begin{array}{l}\text { Lognormal parameter of the mean } \\
\text { PNSD }\end{array}$ & UB & Hussein et al. (2005) \\
\hline $3-20$ & Freshly formed particles & Mode of PNSD & $\mathrm{RB}$ & Laaksonen et al. (2005) \\
\hline 9,12 & Photochemical nucleation & $\begin{array}{l}\text { Modal diameter by fitting PC to log- } \\
\text { normal PNSD }\end{array}$ & $\mathrm{RB}$ & $\begin{array}{l}\text { Chan and Mozurkewich } \\
(2007 \mathrm{~b})\end{array}$ \\
\hline $5-20$ & Rural background NM & Modal size range by multi-site PCA & $\mathrm{RB}$ & This work \\
\hline \multicolumn{5}{|c|}{ Nucleation mode VI } \\
\hline 25 & Traffic influenced aerosol & Mode of volume size distribution & UB & Hidy (1975) \\
\hline $20-40$ & $\begin{array}{l}\text { Gasoline exhausts and Aging of well- } \\
\text { mixed urban aerosol }\end{array}$ & Mode of PNSD & $\begin{array}{l}\text { RS, } \\
\text { UB }\end{array}$ & Morawska et al. (1999) \\
\hline $9-30$ & Aged nucleation mode & Lognormal fitting parameter & $\mathrm{RB}$ & Birmili et al. (2001) \\
\hline $10-35$ & Unknown, but possibly fossil fuel source & Mode of PNSD & UB & Woo et al. (2001) \\
\hline ca. 20 & $\begin{array}{l}\text { Nano-size range particles in connection } \\
\text { with diesel vehicles }\end{array}$ & Maximum in average PNSD & $\mathrm{RS}$ & Wåhlin et al. (2001) \\
\hline $25-50$ & Decay of freeway emissions & Mode of PNSD & $\begin{array}{l}\text { RS, } \\
\text { UB }\end{array}$ & Zhu et al. (2002) \\
\hline $14-26$ & Very small particles at high vehicle speeds & Mode of PNSD & RS & Kittelson et al. (2004) \\
\hline 17.7 & Nucleation mode & GMD of the mode fitting parameters & UB & Hussein et al. (2004) \\
\hline $15-20$ & Mode of the traffic-related PNSD & Maximum in PNSD & UB & Stanier et al. (2004) \\
\hline $10-50$ & Fresh emissions from the traffic & PC mode by PCA & RS & Janhäll et al. (2004) \\
\hline $20-30$ & Nucleation mode & Mode of PNSD & $\begin{array}{l}\mathrm{UB} \\
\mathrm{RB}\end{array}$ & Ketzel et al. (2004) \\
\hline $20-50$ & Downwind the highway & Maximum in PNSD & RS & Zhang et al. (2004) \\
\hline 22 & $\begin{array}{l}\text { Nucleation mode particles from exhaust } \\
\text { gas cooling }\end{array}$ & Maximum in PNSD & RS & Imhof et al. (2005) \\
\hline ca. 20 & Emissions from heavy-duty diesel vehicles & Mode of PNSD & $\mathrm{RS}$ & Yao et al. (2006) \\
\hline $15-19$ & Photochemical nucleation & Lognormal fits of PCA factor loadings & $\begin{array}{l}\mathrm{RB} \\
\mathrm{UB}\end{array}$ & $\begin{array}{l}\text { Chan and Mozurkewich } \\
(2007 \mathrm{~b})\end{array}$ \\
\hline $27-30$ & - & $\begin{array}{l}\text { Max of moving average correlation } \\
\text { coefficient }\end{array}$ & UB & Gramotnev et al. (2007) \\
\hline $7.5-43$ & $\begin{array}{l}\text { Nucleation2: OC } 68 \% \text {, EC } 19 \% \text {, sulfuric } \\
\text { acid } 7 \% \text {, ammonium sulphate } 6 \%\end{array}$ & Mode of the PNSD & UB & Pohjola et al. (2007) \\
\hline $11-30$ & Aged nucleation & Mode of 11-30 nm particles & $\mathrm{RB}$ & Charron et al. (2007) \\
\hline 18 & Young Aitken mode & $\begin{array}{l}\text { Lognormal modal parameters of } \\
\text { PNSD }\end{array}$ & $\begin{array}{l}\mathrm{RS} \\
\mathrm{UB}\end{array}$ & Birmili et al. (2009) \\
\hline $10-50$ & Aged urban NM & Modal size range by multi-site PCA & $\begin{array}{l}\mathrm{RB} \\
\mathrm{UB}\end{array}$ & This work \\
\hline
\end{tabular}

${ }^{1}$ PNSD: particle number size distribution, PC: principal component, PCA: principal component analysis, DGN: geometric number mean size, GMD: geometric mean diameter. ${ }^{2}$ RS: roadside, UB: urban background, RB: regional background. 
mainly urban (PC3 in Fig. 5c, and PC5 and PC13 in Fig. 5c) and rural (PC8 in Fig. 5c, and PC7 in Fig. 5d) observations. The scores of the urban-type PCs were higher during the early morning, while the rural types scored higher in the late evening (Fig. 6). Although distinct, certain temporal correlations were identified between these components that obviously result from common source processes (Sect. 4.3.3).

In the rural area, which is less affected by direct traffic emissions, smaller-sized Aitken particles (PC7 of STA3) are likely to have grown by coagulation and/or condensation from nucleation mode particles (PC4 of STA3). In contrast, urban-area Aitken particles (PC13 of STA3) could have started their life in the atmosphere as directly emitted traffic particles (PC5 of STA3), subsequently growing by coagulation and/or condensation even throughout periods of lower emissions (as suggested by the lower scores at daytime).

Our analysis suggests the urban Aitken mode particles to encompass a spatial scale of the entire city, or bigger. The interaction between particles emitted directly from the diffusely distributed primary sources (mainly traffic) and those generated by secondary processes seems to generate an Aitken mode that is more persistent and also bigger in particle diameter than the Aitken mode in the rural area. To support this discussion, the literature evidence on Aitken particle modes detected urban areas is summarised in Table $4 \mathrm{~b}$.

\subsubsection{Statistical factors in the nucleation mode range}

Owing to its short life-time, and also high spatial variability, our findings concerning the nucleation mode were the most diverse. Three main size ranges were identified, where the particles originating from recent nucleation behaved rather differently: $<5 \mathrm{~nm}, 3-20 \mathrm{~nm}$, and $10-50 \mathrm{~nm}$ (Table 3). The highest spatio-temporal correlation between different observation sites occurred in the size interval $10-50 \mathrm{~nm}$. The corresponding statistical component (PC2 of STA7, Fig. 5a) suggests a spatially very homogeneous nucleation mode. The identification of this nucleation mode component was, however, not unambiguous when comparing different statistical analyses: In STA4, which encompasses less sites than STA7 but a significantly longer time period, this nucleation mode component (PC2) has a much lower variance. In fact, the difference of variance is partly due to the presence of components relating to smaller particles (Fig. 5c). (One might note the lower cut-off size of the distributions being $10 \mathrm{~nm}$ in STA7 compared to $3 \mathrm{~nm}$ in STA4.) Besides, we presume that the dominating role of the $10-50 \mathrm{~nm}$ component (PC2) in STA7 might also be caused by the high frequency of regional new particle formation events, such as in Fig. 3b, during the corresponding measurement period in 2005. The high spatial homogeneity of regional particle formation events under sunny conditions, whose particle concentrations may supersede the concentrations of traffic-generated particles, was previously observed by (Wehner et al., 2007).
Robust results were obtained by the analysis of the biennial data set. Three distinct components govern the 3-20 nm size range - PC2, PC4, and PC6 in STA3 (Fig. 5d). We attribute this split-up to distinct particle formation processes due to the very different conditions of the three measurement sites, which are representive of roadside, urban background, and rural area, but in the case of the rural site also to its spatial distance from the city $(50 \mathrm{~km})$.

To better differentiate between the nucleation mode components of STA3, average diurnal cycles of their scores are plotted in Fig. 8. On weekends, the scores of all nucleation mode components show very similar diurnal cycles peaking around mid-day (Fig. 8b). This is an argument for the components representing mainly the photochemically induced particle formation. (Although, it needs to be noted that traffic emissions reach a maximum during mid-day on weekends as well.) During weekdays, in contrast, the cycles are multiple-peaked, most evident in PC2: A first peak (06:00-08:00) coincides with high traffic volumes in the rush hour. A second peak occurs after mid-day, coinciding with the cycle seen on the weekend. We therefore associate the mid-day peak again with secondary particle formation due to photochemical processes. In the case of PC8, which is the most traffic-correlated component, a third peak can be seen around 16:00-18:00, which coincides with the evening rush hour. A conclusion is that without a consideration of the time of day (or the level of solar radiation), the size distribution PCs cannot absolutely separate direct traffic emissions and photochemical particle formation.

We attribute PC2 of STA3 to urban traffic emissions which have already undergone processing on the time-scale of several tens of minutes. This is for multiple reasons: This component exhibits a high temporal variability (Fig. 2) and a clear correlation with larger particles (up to $100 \mathrm{~nm}$ ), which both point to vehicle exhaust as a source, much alike PC8 of STA3. On the other hand, it is reasonably different from PC4 of STA1 (centered around diameters $<5 \mathrm{~nm}$; cf. Fig. $4 \mathrm{a}$ and Table 3), which represents engine-related nucleation mode particles (Kittelson, 1998) at the same street canyon site (Eisenbahnstrasse). The score of PC4 (of STA1) is more variable in time, and only correlates with the traffic density, and the vertical wind speed. In the case of PC2 (of STA3), a clear dependency on meteorology was found, and a much larger spatial correlation - factor loadings up to 0.7 in the city and still $>0.3$ at the rural site. Chan and Mozurkewich (2007a) achieved, albeit for a single-site analysis only, very similar results. This finding indicates the existence of an additional urban-scale nucleation mode strongly influenced by traffic emissions (Sioutas et al., 2005).

The component PC4 of STA3 (Fig. 5d) indicates a particle nucleation process that is more intense over the rural compared to the urban atmosphere (cf. its signature in Fig. 7b-c). With respect to the other nucleation mode components (PC2 and PC6 of STA3), this rural-type PC4 has the lowest temporal and spatial $(0.2-0.4)$ correlations. This can possibly be 

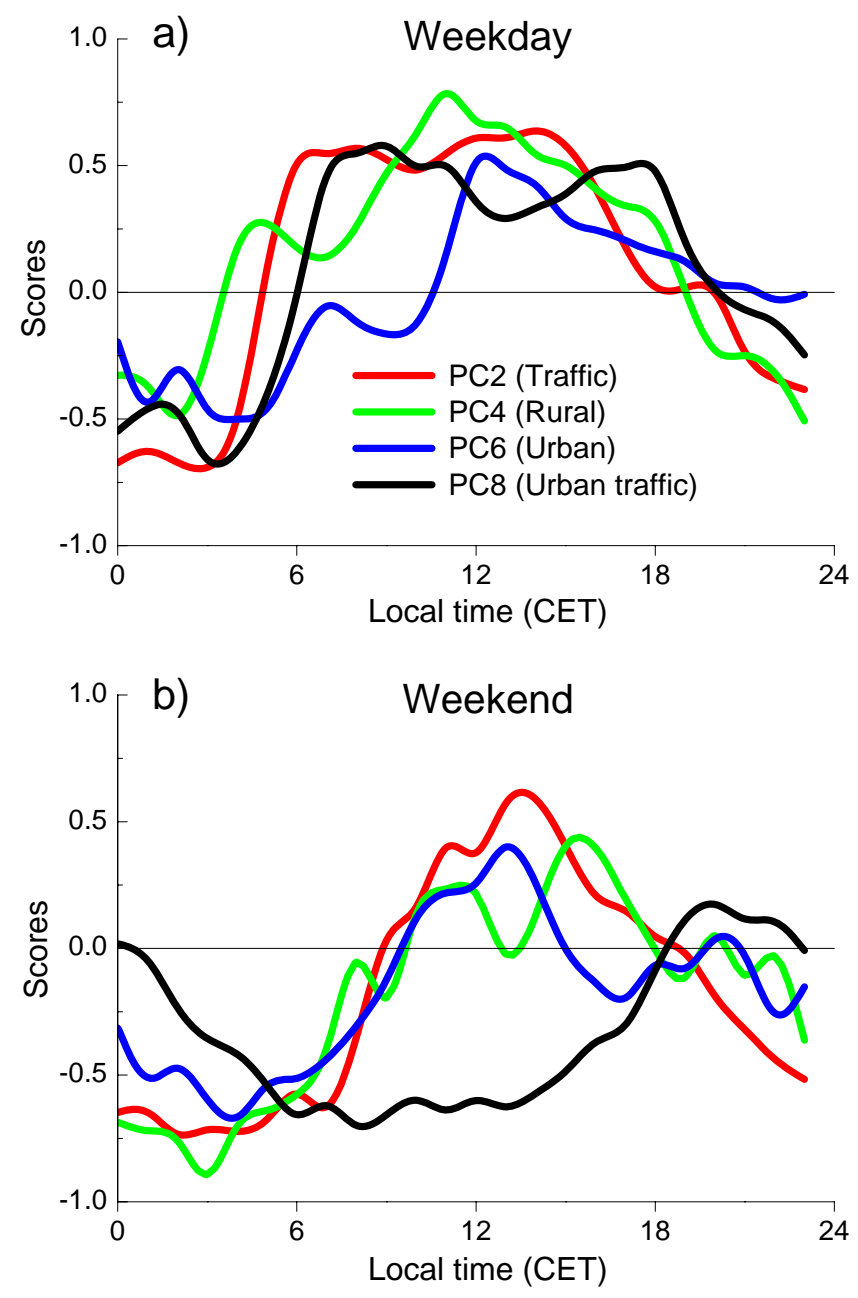

Fig. 8. Diurnal cycles of the scores of PC2, PC4, PC6 (associated with nucleation modes), and PC8 (associated with urban traffic) extracted from in STA3 (Table 3). Weekday (a) and weekend (b) mean scores are shown.

explained by the rural site being the farthest from the urban area, and the spatial scale of PC4 (of STA3) being lower than the distance from the different urban sites within Leipzig. A remarkable finding was its scores were higher on weekdays (Fig. 8a), that is to say that the occurrence of a nucleation mode at the rural site was more (statistically) frequent during weekdays compared to the weekends. Although we have no solid evidence for it, this result suggests a possible involvement in the nucleation mechanism at the rural site of anthropogenic emissions, which have a weekly cycle in the continental atmosphere.

The urban-type PC6 of STA3 (Fig. 5d) has the highest temporal correlation and an intermediate spatial variability (0.4-0.7). This is probably due to its smaller distance from the closer urban sites. It has higher scores at midday like the rural-type PC4 (of STA3), but it is still modulated by the typical structure of the urban traffic PC8 (of STA3) (Fig. 8).
Like the rural-type PC4, it is higher during large-scale new particle formation and growth events (e.g., Fig. 3a), and is directly time correlated with temperature and global radiation, as well as with Aitken mode PCs. Like the traffic-type PC2 (of STA3), it is enhanced by higher concentrations of gaseous pollutants (cf. Table 3): The highest scores occur for the observation site downwind of the city. More interestingly, this is the only urban-scale and long-term nucleation mode PC with a mode peak diameter below $8 \mathrm{~nm}$ (see Fig. 5d), and the only one with a significant correlation with $\mathrm{SO}_{2}$ at daytime. Previous works pointed out to the relevance of particle formation in plumes containing $\mathrm{SO}_{2}$ (Kerminen and Wexler, 1996; Brock et al., 2002). $\mathrm{H}_{2} \mathrm{SO}_{4}$, a product of $\mathrm{SO}_{2}$ oxidation, has long been considered a nucleation precursor (Doyle, 1961). (It is probable likely that in the case of the rural type PC4, this correlation is masked by the fact that $\mathrm{SO}_{2}$ was measured only far from the rural site.) Previous studies in rural atmospheres in Germany suggested combined statistical effects of both, $\mathrm{SO}_{2}$ mixing ratios as well as solar radiation for the onset of photochemically-induced particle formation (Birmili and Wiedensohler, 2000; Birmili et al., 2003).

In summary, the urban nucleation mode tends to be the more variable in time and space the smaller the particles are. Particles below $5 \mathrm{~nm}$ seem to vary on spatio-temporal scales smaller than it can be studied by our experimental set-up. The growth of the particles $<5 \mathrm{~nm}$ into larger sizes appears to be driven by processes on a time scale up to a few hours corresponding to a spatial scale of a few kilometers. Nucleation mode particles $>10 \mathrm{~nm}$ can be homogeneous on a scale between a few kilometers (the maximum distance between our urban sites was $6 \mathrm{~km}$ ) to $50 \mathrm{~km}$ (i.e. including the rural site Melpiz), and possibly more.

\subsection{A paradigm for the spatio-temporal variability of urban aerosol particles}

The observed spatio-temporal variability of PNSD reflects the contemporary occurrence of a multitude of processes, from aerosol micro-physics and chemistry, to meteorology and air pollution, and aerosol generation in the near-field of emission sources such as traffic. Understanding how every single process separately contributed in shaping the PNSD is not easy on the basis of stationary measurements.

We noted the relevance of traffic emissions and specific gaseous compounds on the different aerosol populations, represented by our principal components (Table 3). Traffic does not only seem to be a major source of UFPs at roadside, but also to affect the population of sub- $\mu \mathrm{m}$ particles in the whole region. We mentioned previously the influence of the $\mathrm{SO}_{2}$ concentrations on the urban-type nucleation mode. We also mentioned that at the background sites the newly formed particles correlated directly with ozone, and inversely with $\mathrm{NO}_{\mathrm{x}}$ and benzene concentrations (Table 3 ). This is an indication of the relevance of "photochemical aging" processes (VOC oxidation by ozone, and production of condensable organic 


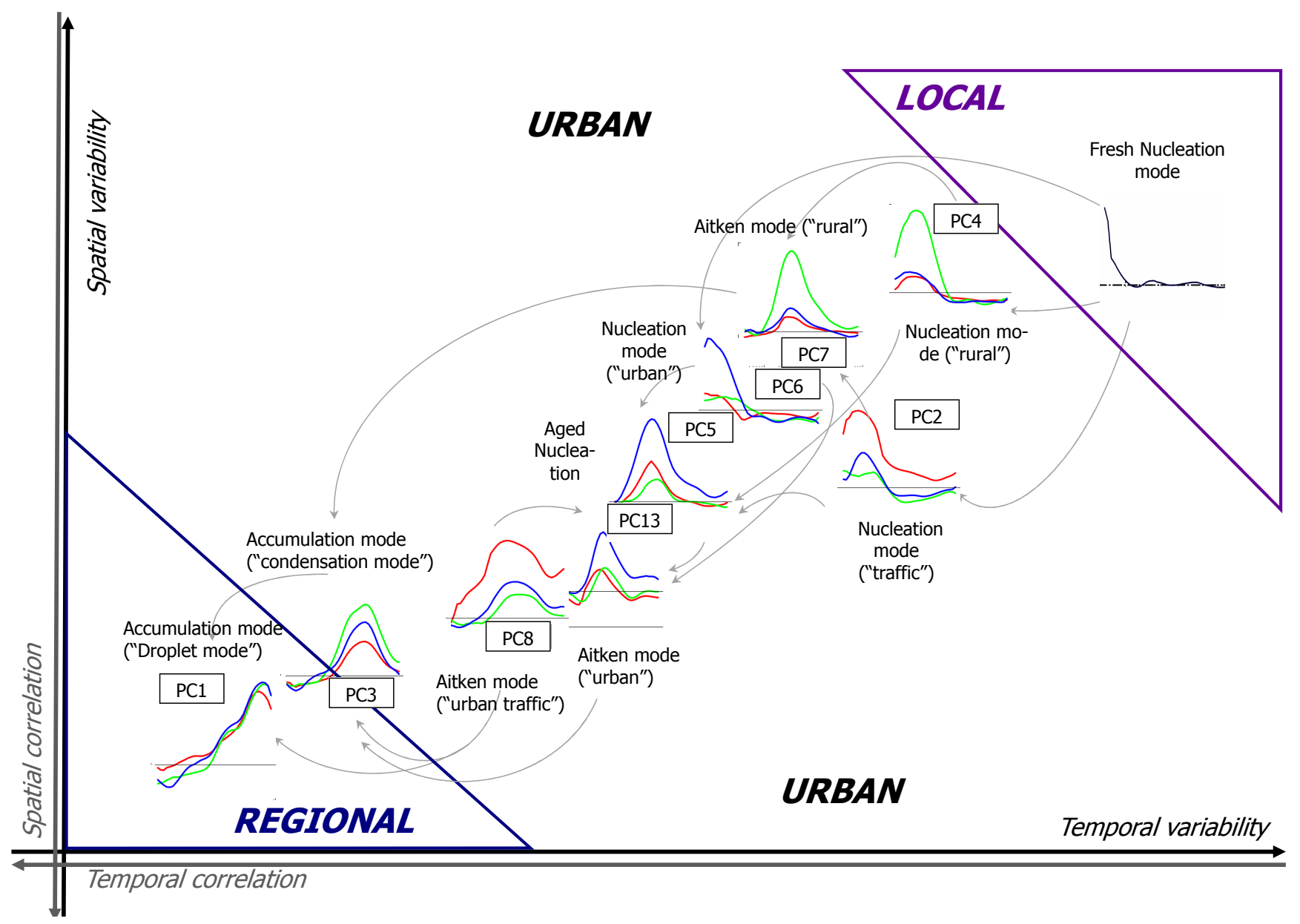

Fig. 9. Paradigm of aerosol particle modes and their evolution in space and time in the coordinate systems of variability (black axis) and correlation (grey axis). The PCs shown refer to those derived from STA3 (see Fig. 5a)

species (Kulmala et al., 2003)) in shaping the PNSD in the smaller particle size ranges and far enough from direct traffic emissions. Every single statistical correlation observed was, nevertheless, lower than the intra-correlations among the PCs (cf. Sect. 4.3.3 and Table 3). We interpret this as an argument for the PNSD variability to be primarily governed by intradynamic large-scale processes of aerosol aging, in agreement with the aerosol general dynamic equation.

The information gathered during this work led to the development of a paradigm describing the evolution of the urban sub- $\mu$ m aerosol (see Fig. 9. It shows the extracted persistent PNSD components in terms of their spatial and temporal variability (or correlations) calculated here. In the urban area, the spatial and temporal variability of a particle population increases with decreasing particle diameter. At comparable diameters, particles originating from primary emissions show a lower variability than such from secondary sources. Larger particles scavenge smaller ones. Less obvious, primary particles reduce the number of secondary particles with similar diameters, and increase the number of particles with larger diameters. The two borderlines of the urban aerosol (i.e. the separation urban/regional, and urban/local) are represented by the condensation mode particles on one side, and the fresh nucleation mode particles on the other side. This implies both that urban-aged aerosol is prevalently formed by condensation mode particles, and that fresh nucleation mode particles have potentially the highest spatio-temporal variability in an urban area.

\subsection{Implication for exposure and monitoring of ultra- fine particles}

The higher-variance PCs from single site analysis (STA1) were always a sub-group of the higher-variance PCs of multiple-site STAs (cf. Figs. 4 and 5a). This indicates both the relevance of large-scale and persistent components in shaping the PNSD, and the difficulty to identify such components by monitoring at a single site alone. The major conclusion is that a comprehensive understanding of all components of variability of PNSD at a single site calls for observations at multiple points. 
Our results suggest that: traffic sites are poorly representative of Aitken and condensation mode particles, too masked by local emissions (cf. Sect. 4.4 and Fig. 7a); pure secondary Aitken mode particles (i.e. rural Aitken) are inadequately measured in the urban area; and droplet mode particles are equally represented at all sites. We speculate that the characterization of all persistent and large-scale components of the PNSD urban variability requires a minimum of four observation sites: one roadside, two different urban background, and one rural (STA4). (Obvious, this is expected for an urban area with no local industrial sources.) In fact, we believe that the Aitken and accumulation mode components require only three representative sites (roadside, urban background, and rural, cf. STA3), but that the nucleation mode components (both the "traffic" and "urban" PC) require more than the three urban observation spots (down to $3 \mathrm{~nm}$ ) used in this study (STA4).

\section{Conclusions}

Number size distributions of atmospheric aerosol particles (maximum size range 3-800 nm) were measured simultaneously at a maximum of eight observation sites in and around a city in Central Europe (Leipzig, Germany) during two main experiments ( 2 years at 3 sites; 1 month at 7 sites).

A general observation was that the particle number size distribution varies in time and space in a complex fashion as a result of interaction between local and far-range sources, and the meteorological conditions. To identify statistically independent factors in the urban aerosol, a principal component analysis was conducted encompassing aerosol, gas phase, and meteorological parameters from the multiple sites. Several of the resulting principal components, outstanding with respect to their temporal persistence and spatial coverage, could be associated with aerosol particle modes. Their analysis yielded a surprising wealth of statistical aerosol components occurring in the urban atmosphere over one single city. Meanwhile, satisfactory physical explanations could be found for the components with the greatest temporal persistence and spatial coverage.

A first accumulation mode ("droplet mode", 300-800 nm) is considered to be the result of liquid phase processes and far-range transport. A second accumulation mode ("condensation mode", 90-250 nm) is considered to represent urban aerosols resulting from primary emissions as well as aging through condensation and coagulation.

The Aitken mode (30-90 nm) is split-up in an urban and a rural component. The urban one has a spatial scale as large as the all city, and results from the interaction of primary and secondary sources. It is more persistent in time and with larger mode diameters than the rural one.

The nucleation mode could be broken down into three size intervals corresponding to different behaviors: $<5 \mathrm{~nm}, 3-$ $20 \mathrm{~nm}$, and $>10 \mathrm{~nm}$. The larger the diameters, the higher the spatio-temporal correlations. The $3-20 \mathrm{~nm}$ could be separated in further components: traffic type (4-20 nm) linked to the atmospheric processing of primary emissions, and urban and rural types (3-15 and 5-20 nm) linked to photochemically induced particle formation in the urban and rural area, respectively.

Even if these PCs are not truly Lagrangian in that one always follows the other in time, their analysis could help in understanding the aerosol evolution in a Lagrangian perspective. A paradigm on the behaviour of sub- $\mu \mathrm{m}$ urban aerosol particles is in turn proposed, showing the urban PNSD to be primarily governed by intra-dynamic processes of aerosol aging with a larger scale. Based on the results of the study, recommendations can be drawn on how many measurement sites are necessary to monitor individual aerosol components across the entire area of a city.

This study provides information on both, the overall spatial variation of particle number size distributions in an urban area, and the occurring inter-site correlations, which might be useful for particle exposure assessment, atmospheric process identification, and for the validation of numerical models describing aerosol emission, formation, and transport. Concrete plans for a follow-up experiment in 2010 in Leipzig and Dresden have been devised, and will be accompanied by multiple scale dispersion modelling.

Acknowledgements. The PURAT project (Particles in the urban atmosphere: Behaviour of fine and ultrafine particles, their spatial variation and relationships with local policy action) was supported by the EU Marie Curie Reintegration Grant FP6-2002-Mobility-11 contract No. 510583. We also thank Dieter Bake, German Federal Environment Agency (UBA), within the UFOPLAN contract 20442204/03. Assistance with measurements: K. Lupa, K. Stopfkuchen, M. Merkel (IfT) and M. Schilde (UFZ). Measurement at the LfUG sites were kindly provided by Udo König, Sächsisches Landesamt für Umwelt und Geologie (Saxonian Office for the Environment and Geology, Dresden, Germany). Figure 1 was prepared by Robert Otto. We thank Jonas Heseman for his precious help, and the generous support of I. Allegrini (CNR-IIA).

V.-M. Kerminen

\section{References}

Andronache, C.: Precipitation removal of ultrafine aerosol particles from the atmospheric boundary layer, J. Geophys. Res., 109, D16S07, doi:10.1029/2003JD004050, 2004.

Alam, A., Shi, J. P., and Harrison, R. M.: Observations of new particle formation in urban air, J. Geophys. Res., 108(D3), 4093, doi:10.1029/2001JD001417, 2003.

Birmili, W., Stratmann, F., and Wiedensohler, A.: Design of a DMA-based size spectrometer for a large particle size range and stable operation, J. Aerosol Sci., 30, 549-553, 1999.

Birmili, W. and Wiedensohler, A.: New particle formation in the continental boundary layer: meteorological and gas phase parameter influence, Geophys. Res. Lett., 27, 3325-3328, 2000. 
Birmili, W., Wiedensohler, A., Heintzenberg, J., and Lehmann, K.: Atmospheric particle number size distribution in Central Europe: Statistical relations to air masses and meteorology, J. Geophys. Res., 106(D23), 32005-32018, 2001.

Birmili, W., Berresheim, H., Plass-Dülmer, C., et al.: The Hohenpeissenberg aerosol formation experiment (HAFEX): a longterm study including size-resolved aerosol, $\mathrm{H}_{2} \mathrm{SO}_{4}, \mathrm{OH}$, and monoterpenes measurements, Atmos. Chem. Phys., 3, 361-376, 2003, http://www.atmos-chem-phys.net/3/361/2003/.

Birmili, W., Alaviippola, B., Hinneburg, D., et al.: Dispersion of traffic-related exhaust particles near the Berlin urban motorway: estimation of fleet emission factors, Atmos. Chem. Phys., 9, 2355-2374, 2009, http://www.atmos-chemphys.net/9/2355/2009/.

Brock, C. A., Trainer, M., Ryerson, T. B., et al.: Particle growth in plumes of coal-fired power plants, J. Geophys. Res., 107(D12), 4155, doi:10.1029/2001JD001062, 2002.

Bukowiecki, N., Kittelson, D. B., Watts, W. F., et al.: Real-time characterization of ultrafine and accumulation mode particles in ambient combustion aerosols. J. Aerosol Sci. 33, 1139-1154, 2002.

Bukowiecki, N., Dommen, J., Prévôt, A. S. H., Weingartner, E., and Baltensperger, U.: Fine and ultrafine particles in the Zürich (Switzerland) area measured with a mobile laboratory: an assessment of the seasonal and regional variation throughout a year, Atmos. Chem. Phys., 3, 1477-1494, 2003, http://www.atmos-chem-phys.net/3/1477/2003/.

Chan, T. W. and Mozurkewich, M.: Application of absolute principal component analysis to size distribution data: identification of particle origins, Atmos. Chem. Phys., 7, 887-897, 2007a, http://www.atmos-chem-phys.net/7/887/2007/.

Chan, T. W. and Mozurkewich, M.: Simplified representation of atmospheric aerosol size distributions using absolute principal component analysis, Atmos. Chem. Phys., 7, 875-886, 2007b, http://www.atmos-chem-phys.net/7/875/2007/.

Charron, A., Birmili, W., and Harrison, R. M.: Factors influencing new particle formation at the rural site, Harwell, United Kingdom, J. Geohys. Res., 112, D14210, doi:10.1029/2007JD008425, 2007.

Cubison, M. J., Ervens, B., Feingold, G., et al.: The influence of chemical composition and mixing state of Los Angeles urban aerosol on CCN number and cloud properties, Atmos. Chem. Phys., 8, 5649-5667, 2008,

http://www.atmos-chem-phys.net/8/5649/2008/.

Doyle, G. J.: Self-nucleation in the sulfuric acid-water system, J. Chem. Phys., 35, 795-799, 1961.

Drewnick, F., Jayne, J. T., Canagaratna, M. R., Worsnop, D. R., and Demerjian, K. L.: Measurement of ambient aerosol composition during the PMTACS-NY 2001 using an aerosol mass spectrometer. Part I: mass concentrations, Aerosol Sci. Technol., 38(S1), 92-103, 2004.

Ebert, M., Weinbruch, S., Hoffmann, P., and Ortner, H. M.: The chemical composition and complex refractive index of rural and urban influenced aerosols determined by individual particle analysis, Atmos. Environ., 38, 6531-6545, 2004.

Eder, B. K.: A principal component analysis of $\mathrm{SO}_{4}$ precipitation concentrations over the eastern United States, Atmos. Environ., 23, 2739-2750, 1989.

Engler, C., Rose, D., Wehner, B., et al.: Size distribu- tions of non-volatile particle residuals $(\mathrm{Dp}<800 \mathrm{~nm})$ at a rural site in Germany and relation to air mass origin, Atmos. Chem. Phys., 7, 5785-5802, 2007, http://www.atmos-chemphys.net/7/5785/2007/.

Gnanadesikan, R.: Methods for statistical data analysis of multivariate observations, John Wiley and Sons, New York, USA, 311 pp., 1977.

Gramotnev, G., Madl, P., Gramotnev, D. K., and Burchill, M. J.: Urban background aerosols: negative correlations of particle modes and fragmentation mechanism, Geophys. Res. Lett., 34, L11811, doi:10.1029/2006GL029109, 2007.

Haywood, J. M. and Boucher, O.: Estimates of the direct and indirect radiative forcing due to tropospheric aerosols: A review, Rev. Geophys., 38, 513-543, 2000.

HEI: Understanding the health effects of components of the particulate matter mix: progress and next steps, Tech. Rep. 4, Health Effects Institute, Boston, MA, USA, 2002.

Heintzenberg, J. Birmili, W., Wiedensohler, A., Nowak, A., and Tuch, T.: Structure, variability and persistence of the submicrometre marine aerosol, Tellus B, 56(4), 357-367, 2004.

Heintzenberg, J., Birmili, W., Theiss, D., and Kisilyakhov, Y.: The atmospheric aerosol over Siberia, as seen from the $300 \mathrm{~m}$ ZOTTO tower, Tellus B, 60(2), 276-285, 2008.

Hering, S. V. and Friedlander, S. K.: Origins of sulfur size distributions in the Los Angeles basin, Atmos. Environ., 16, 2647-2656, 1982.

Hidy, G. M.: Summary of the California aerosol characterisation experiment, J. Air Poll. Control, 25, 1106-1114, 1975.

Hinds, W. C.: Aerosol Technology, 2nd ed., John Wiley and Sons, New York, USA, 1999.

Hoppel, W. A.: Determination of the aerosol size distribution from the mobility distribution of the charged fraction of aerosols, J. Aerosol Sci., 9, 41-54, 1978.

Huang, S., Rahn, K. A., and Arimoto, R.: Testing and optimizing two factor-analysis techniques on aerosol at Narragansett, Rhode Island, Atmos. Environ., 33, 2169-2185, 1999.

Hussein, T., Puustinen, A., Aalto, P., Mäkelä, J., Hämeri, K., and Kulmala, M.: Urban aerosol number size distributions, Atmos. Chem. Phys, 4, 391-411, 2004.

Hussein, T., Hämeri, K., Aalto, P., Paatero, P., and Kulmala, M.: Modal structure and spatial-temporal variations of urban and suburban aerosols in Helsinki, Finland, Atmos. Environ., 39, 1655-1668, 2005.

Imhof, D., Weingartner, E., Ordonez, C., et al.: Real-world emission factors of fine and ultrafine aerosol particles for different traffic situations in Switzerland, Environ. Sci. Technol., 39, 8341-8350, 2005.

Jaenicke, R.: Tropospheric aerosols. In: Hobbs, P. V. Editor. Aerosol-cloud-climate interactions, Academic Press, San Diego, CA, USA, 1-31, 1993.

Janhäll, S., Jonsson, A. M., Molnar, P., Svensson, E., and Hallquist, M.: Size resolved traffic emission factors of submicrometer particles, Atmos. Environ., 38, 4331-4340, 2004.

Jimenez, J. L., Jayne, J. T., Shi, Q., et al.: Ambient aerosol sampling with an Aerosol Mass Spectrometer, J. Geophys. Res., 108(D7), 8425, doi:10:1029/2001JD001213, 2003.

John, W., Wall, S. M., Ondo, J. L., and Winklmayr, W.: Modes in the size distributions of atmospheric inorganic aerosol, Atmos. Environ. 24A, 2349-2359, 1990. 
John, W.: The characteristics of environmental and laboratorygenerated aerosols, in: Aerosol measurement: Principles, techniques and applications, edited by: Willeke, K. and Baron, P. A., Van Nostrand Reinhold, New York, USA, 1993.

Jobson, B. T., Parrish, D. D., Goldan, P., et al.: Spatial and temporal variability of nonmethane hydrocarbon mixing ratios and their relation to photochemical lifetime, J. Geophys. Res., 103(D17), 22617-22628, 1998.

Junge, C. E.: Residence time and variability of tropospheric trace gases, Tellus, 16, 477-488, 1974.

Kerminen, V. M. and Wexler, A. S.: The occurrence of sulfuric acid-water nucleation in plumes: Urban environment, Tellus B, 48, 65-82, 1996.

Ketzel, M. P., Wåhlin, A., Kristensson, E., et al.: Particle size distribution and particle mass measurements at urban, near-city and rural level in the Copenhagen area and Southern Sweden, Atmos. Chem. Phys., 4, 281-292, 2004, http://www.atmos-chem-phys.net/4/281/2004/.

Kittelson, D.: Engines and nanoparticles: A review, J. Aerosol Sci., 29, 575-588, 1998.

Kittelson, D., Johnson, J., Watts, W., et al.: Diesel aerosol sampling in the atmosphere, SAE technical paper series, No. 200001-22212, 2000.

Kittelson, D.B., Watts, W.F., Johnson, J.P.: Nanoparticle emissions on Minnesota highways, Atmos. Env., 38, 9-19, 2004.

Kittelson, D. B., Watts, W. F., Johnson, J. P.: On-road and laboratory evaluation of combustion aerosols - Part 1: Summary of diesel engine results, J. Aerosol Sci., 37, 913-930, 2006.

Klose, S., Birmili, W., Voigtländer, J., et al.: Particle number emissions of motor traffic derived from street canyon measurements in a Central European city, Atmos. Chem. Phys. Discuss., 9, 3763-3809, 2009, http://www.atmos-chem-phys-discuss.net/9/3763/2009/.

Kulmala, M., Suni, T., Lehtinen, K. E. J., et al.: A new feedback mechanism linking forests, aerosols, and climate, Atmos. Chem. Phys., 3, 6093-6107, 2003, http://www.atmos-chem-phys.net/3/6093/2003/.

Kulmala, M., Vehkamäki, H., Petäjä, T., et al.: Formation and growth rates of ultrafine atmospheric particles: A review of observations, J. Aerosol Sci., 35, 143-176, 2004.

Laaksonen, A., Hamed, A., Joutsensaari, J., et al.: Cloud condensation nucleus production from nucleation events at a highly polluted region, Geophys. Res. Lett., 32, L06812, doi:10.1029/2004GL022092, 2005.

Le Canut, P., Andreae, M. O., Harris, G. W., Wienhold, F. G., and Zenker, T.: Airborne studies of emissions from savanna fires in southern Africa - 1. Aerosol emissions measured with a laser optical particle counter, J. Geophys. Res., 101(D19), 23615-23630, 1996.

Liu, S., Hu, M., Wu, Z., et al.: Aerosol number size distribution and new particle formation at a rural/coastal site in Pearl River Delta (PRD) of China, Atmos. Env., 42, 6275-6283, 2008.

Mäkelä, J. M., Koponen, I. K., Aalto, P., and Kulmala, M.: Oneyear data of submicron size modes of tropospheric background aerosol in Southern Finland, J. Aerosol Sci., 31(5), 595-611, 2000.

McFiggans, G., Alfarra, M. R., Allan, J., et al.: Simplification of the representation of the organic component of atmospheric particulates, Faraday Discuss., 130, 341-362, 2005.
McMurry, P. H., Woo, K. S., Weber, R., Chen, D.-R., and Pui, D. Y. H.: Size distributions of 3 to $10 \mathrm{~nm}$ atmospheric particles: Implications for nucleation mechanisms. Phil. Trans. Roy. Soc., Lon., A358, 2625-2642, 2000.

Mejia, J. F., Morawska, L., and Mengersen, K.: Spatial variation in particle number size distributions in a large metropolitan area, Atmos. Chem. Phys., 8, 1127-1138, 2008, http://www.atmos-chem-phys.net/8/1127/2008/.

Meng, Z. and Seinfield, J. H.: On the source of the submicrometer droplet mode of urban and regional aerosols, Aerosol Sci. Technol., 20, 253-265, 1994.

Meszaros, A.: On the size distribution of atmospheric aerosol particles of different composition, Atmos. Environ., 11, 1075-1081, 1977.

Mönkkönen, P., Koponen, I. K., Lehtinen, K. E. J., et al.: Measurements in a highly polluted Asian mega city: observations of aerosol number size distribution, modal parameters and nucleation events, Atmos. Chem. Phys., 5, 57-66, 2005, http://www.atmos-chem-phys.net/5/57/2005/.

Morawska, L., Thomas, S. Bofinger, N. D., Wainwright, D., and Neale, D.: Comprehensive characterisation of aerosols in a subtropical urban atmosphere: Particle size distribution and correlation with gaseous pollutants, Atmos. Environ., 32, 2467-2478, 1998.

Morawska, L., Thomas, S., Jamriska, M., and Johnson, G.: The modality of particle size distributions of environmental aerosols, Atmos. Environ., 33, 4401-4411, 1999.

Morawska, L., Keogh, D. U., Thomas, S. B., and Mengersen, K.: Modality in ambient particle size distributions and its potential as a basis for developing air quality regulation, Atmos. Environ., 42, 1617-1628, 2008.

Morrison, D. F.: Multivariate statistical methods, 2nd ed., McGrawHill, New York, USA, 415 pp., 1976.

Mulaik, S. A.: The foundations of factor analysis, McGraw-Hill, New York, USA, 453 pp., 1972.

Oberdörster, G.: Nanotoxicology: An emerging discipline evolving from studies of ultrafine particles, Env. Health Perspect., 113, 823-839, 2005.

Ondov, J. M. and Wexler, A. S.: Where do particulate toxins reside? An improved paradigm for the structure and dynamics of the urban mid-Atlantic aerosol, Environ. Sci. Technol., 32, 2547-2555, 1998.

Pohjola, M. A., Pirjola, L., Karppinen, A., et al.: Evaluation and modelling of the size fractionated aerosol particle number concentration measurements nearby a major road in Helsinki - Part I: Modelling results within the LIPIKA project, Atmos. Chem. Phys., 7, 4065-4080, 2007, http://www.atmos-chem-phys.net/7/4065/2007/.

Pope, C. A., Burnett, R. T., Thun, M. J., et al.: Lung cancer, cardiopulmonary mortality, and long-term exposure to fine particulate air pollution, J. Aerosol Med., 287, 1132-1141, 2002.

Pugatshova, A., Reinart, A., and Tamm, E.: Features of the multimodal aerosol size distribution depending on the air mass origin in the Baltic region, Atmos. Environ., 41, 4408-4422, 2007.

Puustinen, A., Hämeri, K., Pekkanen, J., et al.: Spatial variation of particle number and mass over four European cities, Atmos. Environ., 41, 6622-6636, 2007.

Ramanathan, V., Crutzen, P. J., Kiehl, J. T., and Rosenfeld, D.: Aerosol, climate, and the hydrological cycle, Science, 294, 
2119-2124, 2001.

Rönkkö, T., Virtanen, A., Kannosto, J., et al.: Nucleation mode particles with a nonvolatile core in the exhaust of a heavy duty diesel vehicle, Environ. Sci. Technol., 41, 6384-6389, 2007.

Schneider, J., Kirchner, U., Borrmann, S., Vogt, R., and Scheer, V.: In situ measurements of particle number concentration, chemically resolved size distributions and black carbon content of traffic-related emissions on German motorways, rural roads and in city traffic, Atmos. Environ., 42, 4257-4268, 2008.

Seinfeld, J. H. and Pandis, S. P.: Atmospheric Chemistry and Physics, 2nd ed., John Wiley, New York, USA, 1232 pp., 2006.

Sioutas, C., Delfino, R. J., and Singh, M.: Exposure assessment for atmospheric ultrafine particles (UFP) and implications in epidemiological research, Environ. Health Perspect. 113, 947-955, 2005.

Stanier, C. O., Khlystov, A. Y., and Pandis, S. N.: Nucleation events during the Pittsburgh air quality study: description and relation to key meteorological, gas phase, and aerosol parameters. Aerosol Sci. Technol., 38, 253-264, 2004.

Stolzenburg, M. R., McMurry, P. H., Sakurai, H., et al.: Growth rates of freshly nucleated atmospheric particles in Atlanta, J. Geophys. Res., 110, D22S05, doi:10.1029/2005JD005935, 2005.

Stott, P. A., Tett, S. F. B., Jones, G. S., et al.: External control of $20^{t h}$ century temperature by natural and anthropogenic forcings, Science, 290, 2133-2137, 2000.

Tuch, T. M., Herbarth, O., Franck, U., et al.: Weak correlation of ultrafine aerosol particle concentrations $<800 \mathrm{~nm}$ between two sites within one city, J. Exp. Sci. Environ., 16, 486-490, 2006.

Tunved, P., Ström, J., and Hansson, H. C.: An investigation of processes controlling the evolution of the boundary layer aerosol size distribution properties at the Swedish background station Aspvreten, Atmos. Chem. Phys., 4, 2581-2592, 2004,

http://www.atmos-chem-phys.net/4/2581/2004/.

Wåhlin, P., Palmgren, F., and van Dingenen, R.: Experimental studies of ultrafine particles in streets and the relationship to traffic, Atmos. Environ., 35(S1), 63-69, 2001.

Wehner, B., Birmili, W., Gnauk, T., and Wiedensohler, A.: Particle number size distributions in a street canyon and their transformation into the urban background: Measurements and a simple model study, Atmos. Environ., 36, 2215-2223, 2002.
Wehner, B. and Wiedensohler, A.: Long term measurements of submicrometer urban aerosols: statistical analysis for correlations with meteorological conditions and trace gases, Atmos. Chem. Phys., 3, 867-879, 2003, http://www.atmos-chemphys.net/3/867/2003/.

Wehner, B., Siebert, H., Stratmann, F., et al.: Horizontal homogeinity and vertical extent of new particle formation events, Tellus B, 59, 362-371, 2007.

Whitby, K. T.: The physical characteristics of sulphur aerosols, Atmos. Environ., 12, 135-159, 1978.

WHO: World Health Report 2002, Tech. Rep., World Health Organisation, Genova, Italy, 2002.

Willeke, K. and Whitby, K. T.: Atmospheric aerosol: size distribution interpretation, J. Air Poll. Control Ass., 15(5), 529-535, 1975.

Williams, P. I., Gallagher, M. W., Choularton, T. W., et al.: Aerosol development and interaction in an urban plume, Aerosol Sci. Technol., 32, 120-126, 2000.

Woo, K. S., Chen, D. R., Pui, D. Y. H., and McMurry, P. H.: Measurements of Atlanta aerosol size distributrions: observations of ultrafine particle events, Aerosol Sci. Technol., 34, 75-87, 2001.

Yao, X. H., Lau, N. T., and Chan, C. K.: On the time-averaging of ultrafine particle number size spectra in vehicular plumes, Atmos. Chem. Phys., 6, 4801-4807, 2006, http://www.atmos-chem-phys.net/6/4801/2006/.

Zhang, K. M., Wexler, A. S., Zhu, Y. F., Hinds W. C., and Sioutas, C.: Evolution of particle number distribution near roadways. Part II: the Road-to-Ambient process, Atmos. Environ., 38, 66556665, 2004.

Zhou, J., Swietlicki, E., Hansson, H. C., and Artaxo, P.: Aerosol particle size distribution and hygroscopic growth measured in the Amazon rain forest during, J. Geophys. Res., 107(D20), 8055, doi:10.1029/2000JD000203, 2002.

Zhu, Y., Hinds, W. C, Kim, S., Shen, S., and Sioutas, C.: Study of ultrafine particles near a major highway with heavy-duty diesel traffic, Atmos. Env., 36, 4323-4335, 2002. 